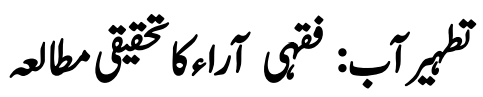

\title{
Water Purification: An Analytical Appraisal of the Viewpoints of Islamic Jurists
}

Mr. Allah Ditta*

Dr. Muhammad Amjad**

\begin{abstract}
Water is the precious blessing of Allah Almighty which is found everywhere in the world. Hence, its usefulness is neglected, and it is wasted unreasonably. Due to its excessive use and human activities, the water sources are becoming polluted too. The rivers, streams and watercourses are too polluted for human use. This situation created water scarcity in the world. Pakistan is also facing acute water deficiency and it will soon become a water stress country from water scarcity state. It demands appropriate measures to treat water as a precious wealth and to use it carefully so that coming generations will not have to face the music. One of those measures is to clean the wastewater so that water scarcity could be eliminated. This paper examines the wastewater treatment in Islamic perspective. In this research, the viewpoints of four Imams regarding water purification have been elaborated and suggestion have been enlightened in brief.
\end{abstract}

Keywords: - Water Purification, Jurists, Islam, viewpoints, Islamic Law, wastewater

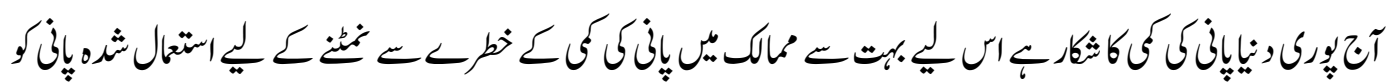

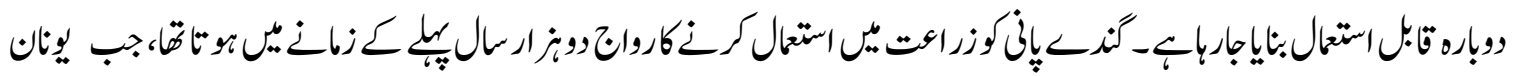

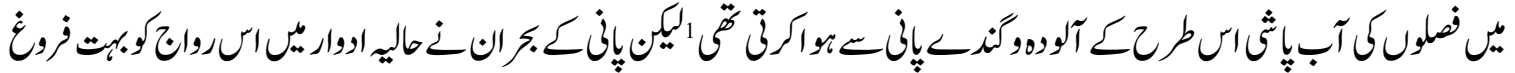

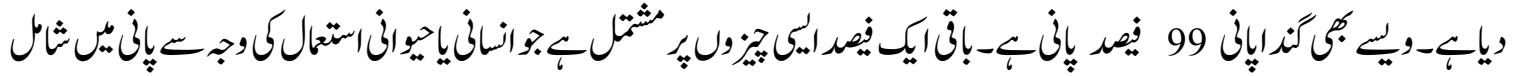

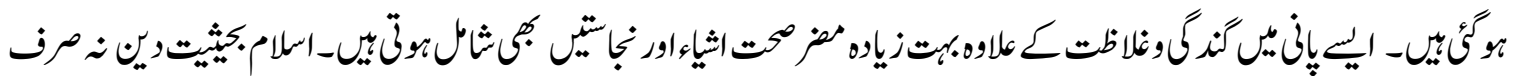

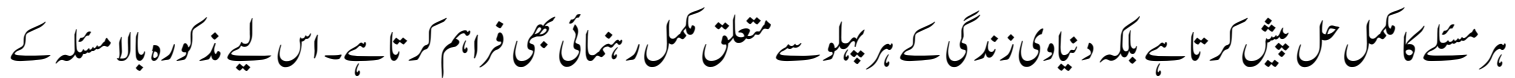

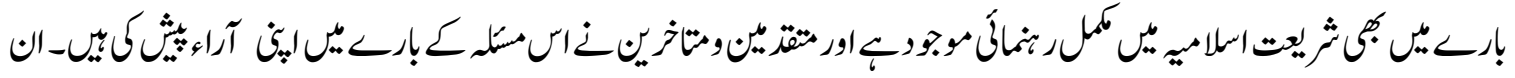

*. Lecturer Islamic Studies Department F.G. Degree College for Women Multan Cantt Email: profabughufran475@gmail.com

${ }^{* *}$. Associate Professor Department of Islamic Studies B.Z.U. Multan, amjad_mailsi@yahoo.com

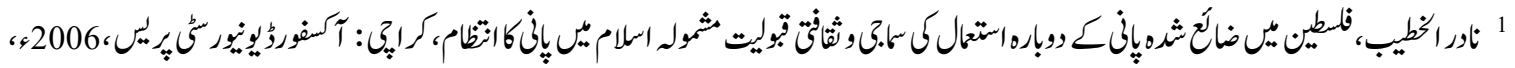

URL: http://alhidayah.wum.edu.pk 


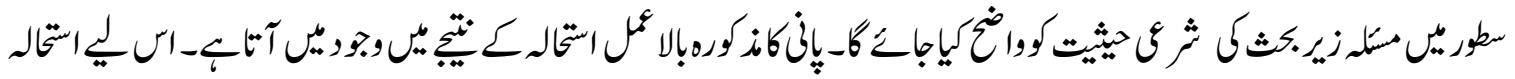

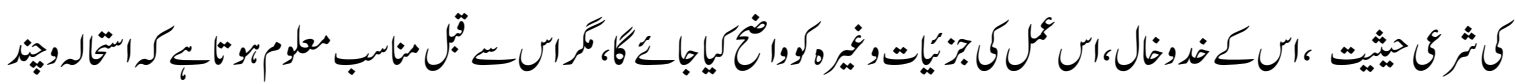

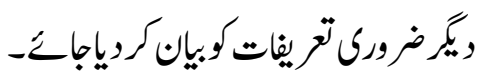

\section{استخالـكالنوى منهوم}

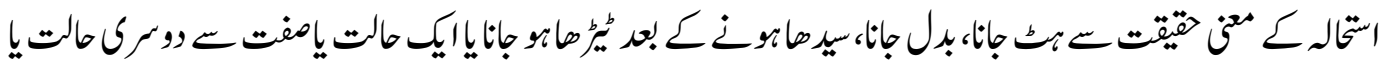

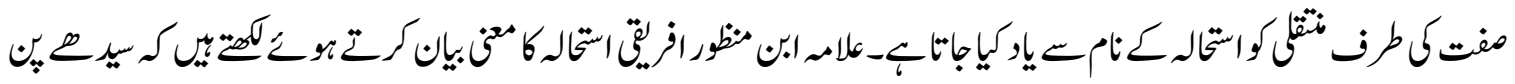

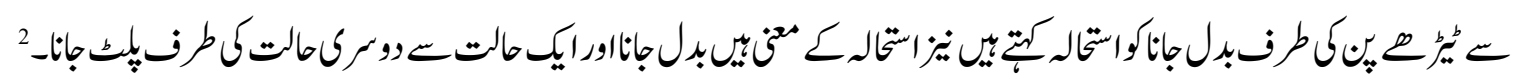

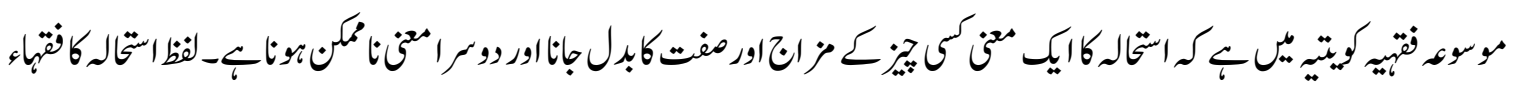

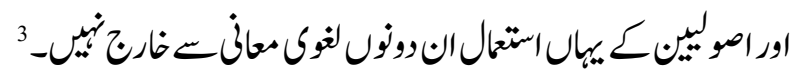

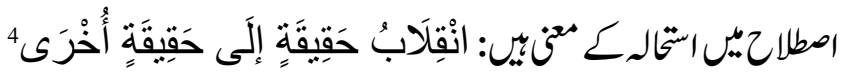

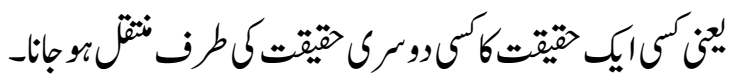

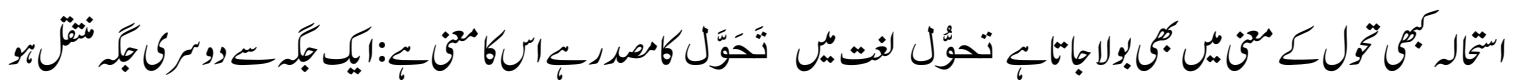

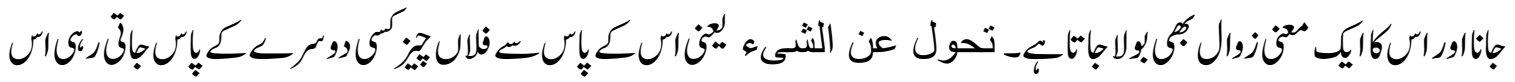

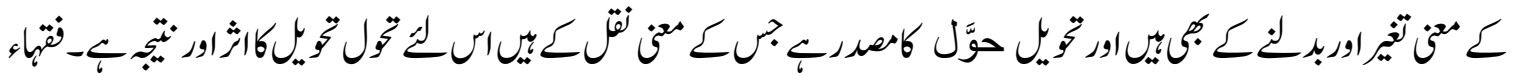

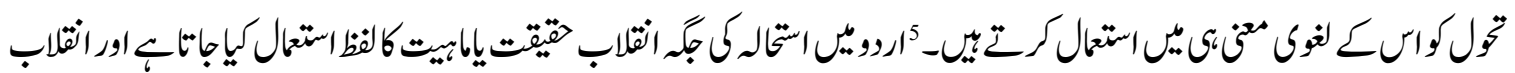

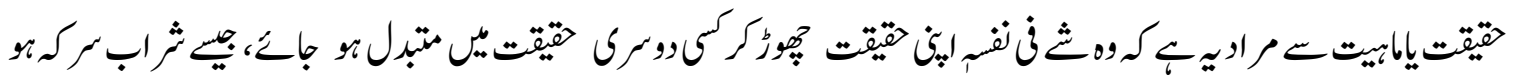

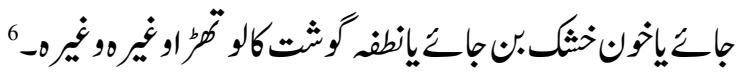

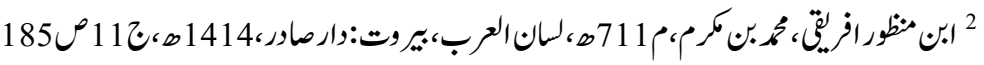

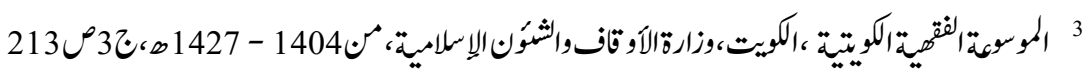

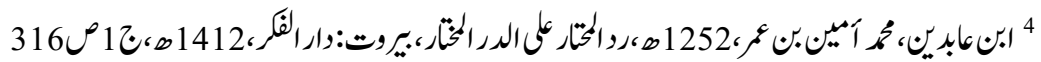
5

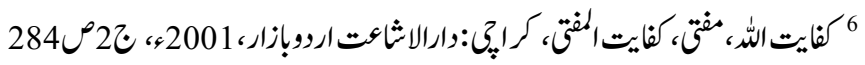




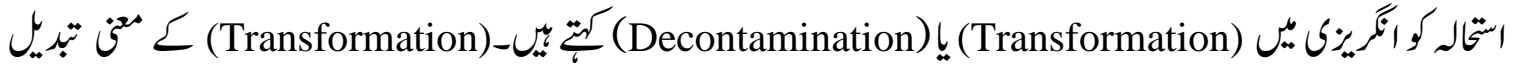

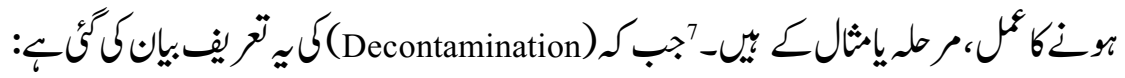

Decontamination is the process of removing contaminants on an object or area, including chemicals, micro-organisms or radioactive substances. This may be achieved by chemical reaction, disinfection or physical removal. It refers to specific action taken to reduce the hazard posed by such contaminants, as opposed to general cleaning 8 .

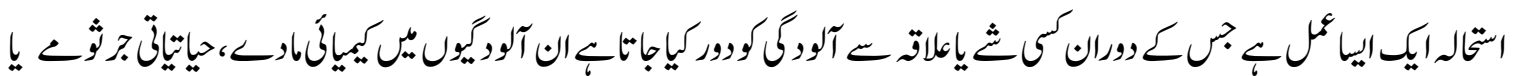

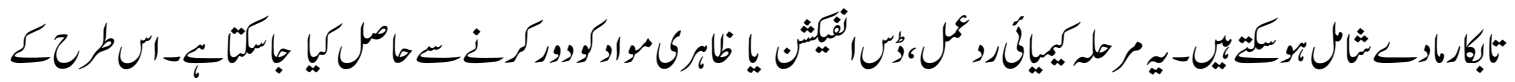

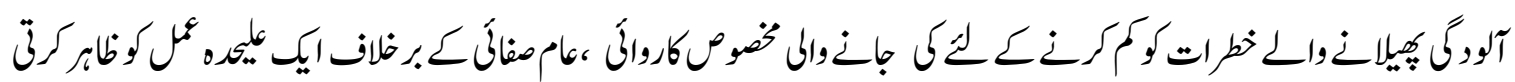

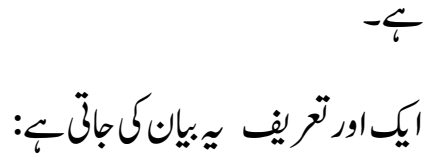

A general term used to describe the destruction or removal of microbial contamination to render an item or the environment safe. The term decontamination includes sterilisation, disinfection and cleaning. ${ }^{9}$

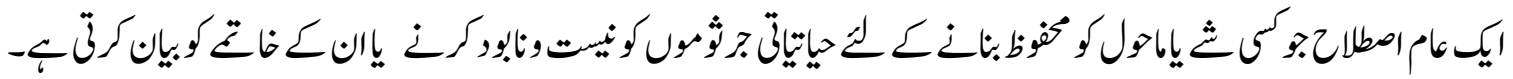

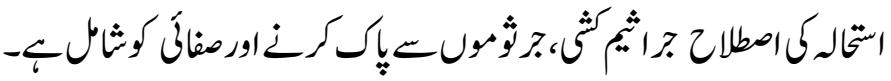

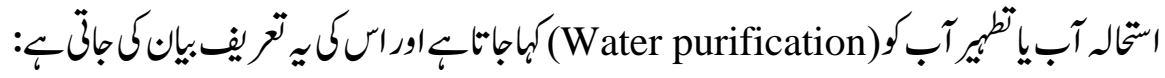

Water purification is the process of removing undesirable chemicals, biological contaminants, suspended solids, and gases from water. ${ }^{10}$

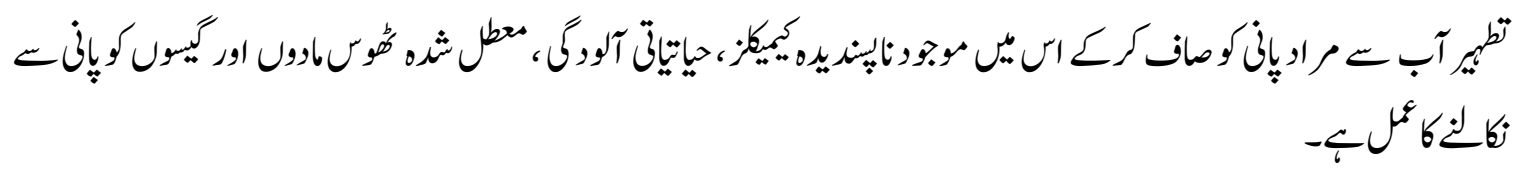

7 https://www.merriam-webster.com/dictionary/transformation (accessed on 12-12-20 at $11: 25 \mathrm{pm})$

8 https://en.wikipedia.org/wiki/Decontamination (accessed on 12-12-20 at 8:20 pm)

9 Decontamination - Cleaning, Disinfection and Sterilisation, Version 1.1(UK: NHS Foundation Trust, April 2019) p.2

${ }^{10}$ https://en.wikipedia.org/wiki/Water_purification (accessed on 12-12-20 at 7:55 pm)

URL: http://alhidayah.wum.edu.pk 


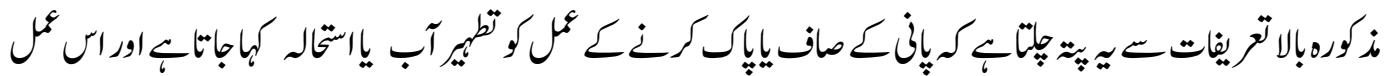

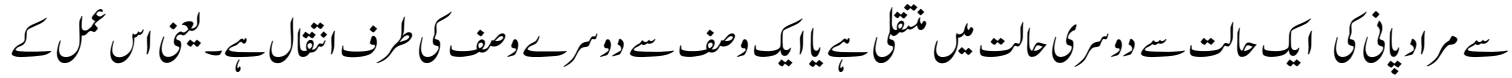

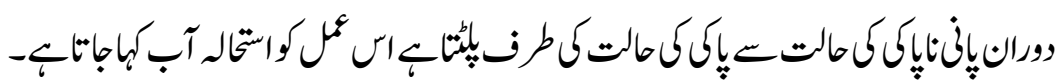

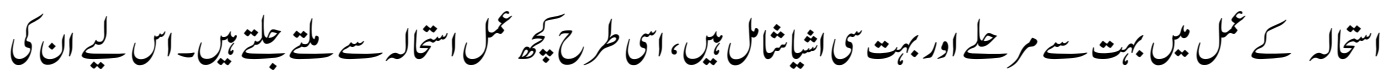

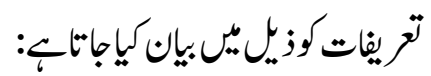

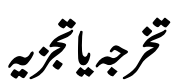

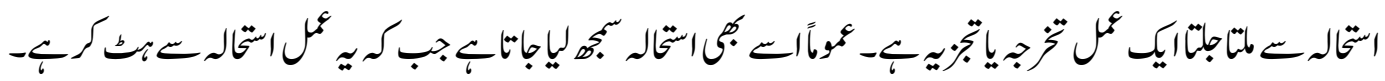

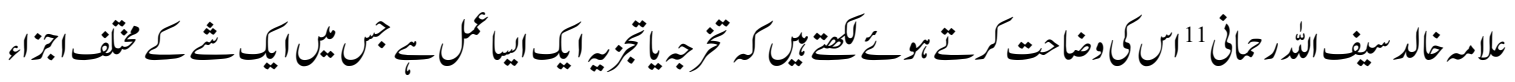

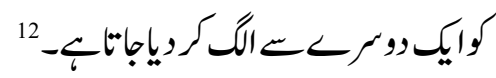

آلورهيأن

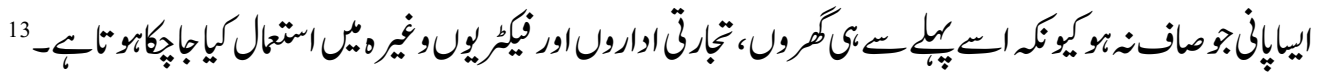

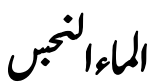

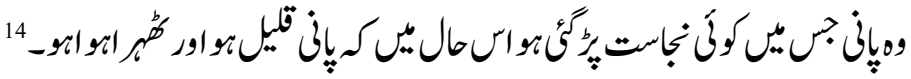

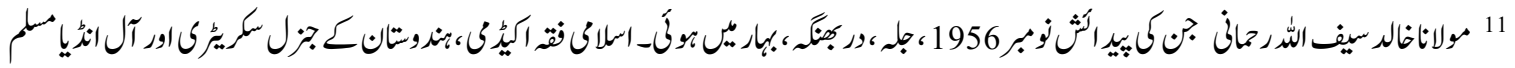

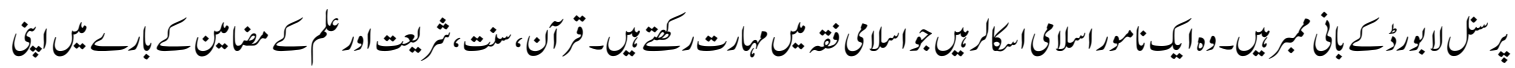

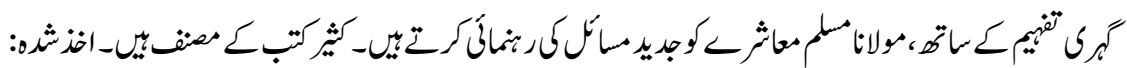
http://khalidrahmani.in/english/about_moulana/ (accessed on 25-12-2020)

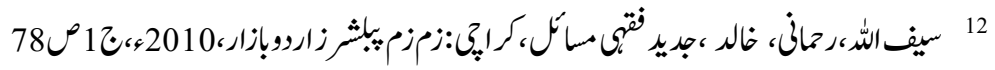

${ }^{13}$ https://www.google.com/amp/s/dictionary.cambridge.org/amp/english/waste-water (accessed on 10-10-2020 at 11:00 am)

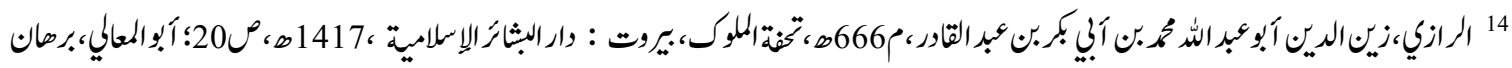

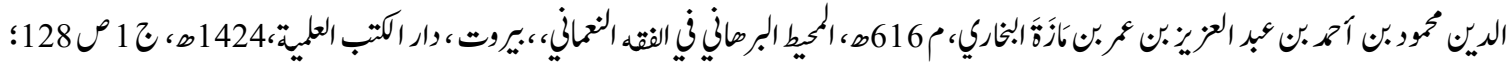

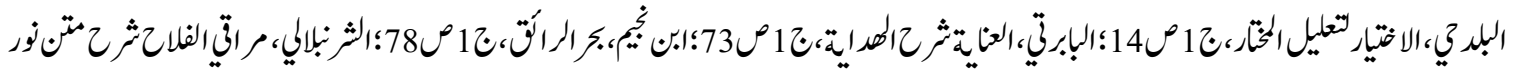

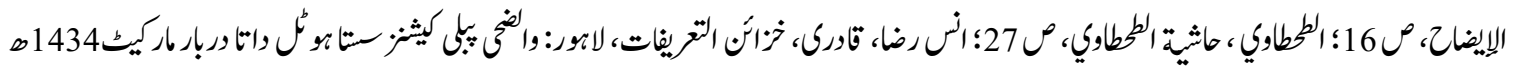
313 •थ2013/ 


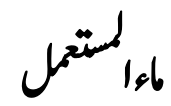

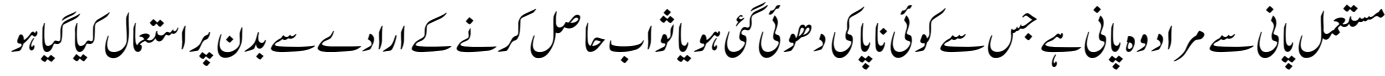
ـ

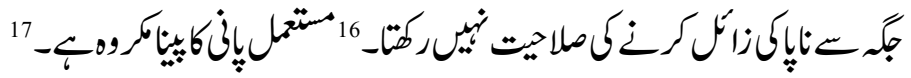

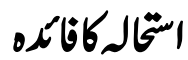

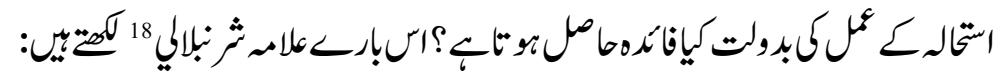

والاستحالة تطهر الأعيان النجسة كالميتة إذا صارت ملحا والعذرة ترابا أو رمادا19

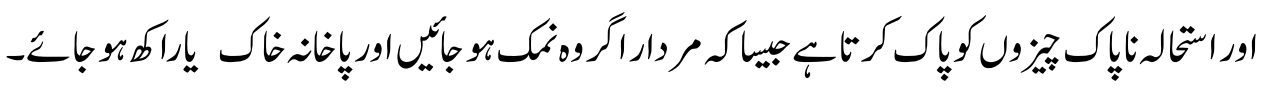

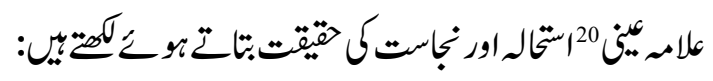

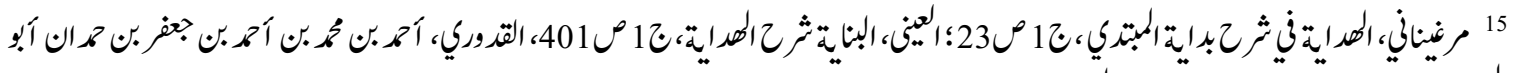

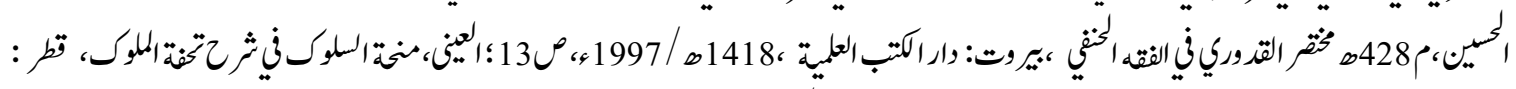

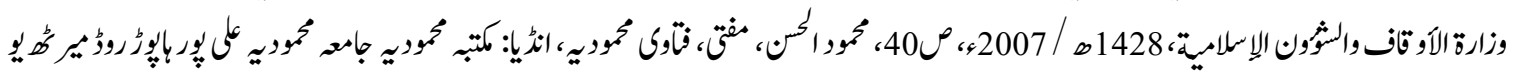

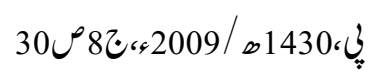

16 17

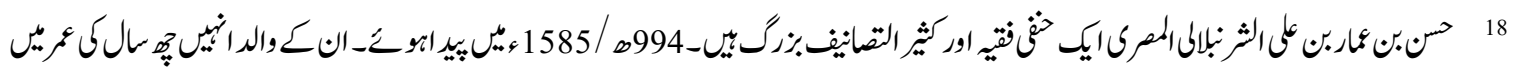

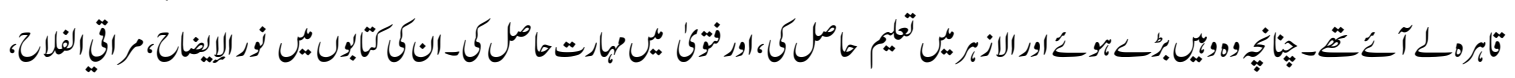

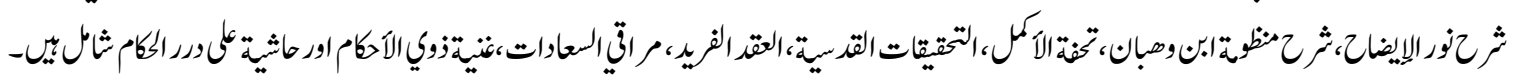

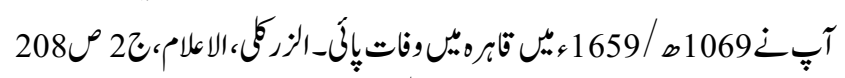

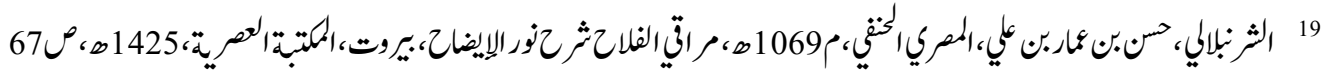

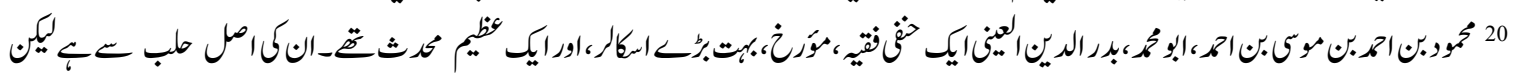

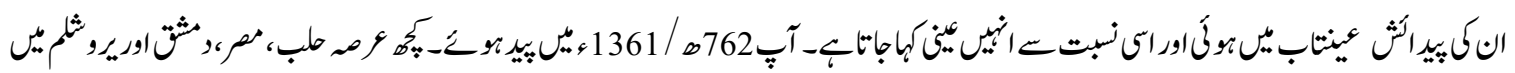

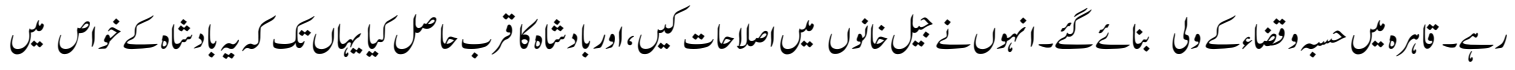

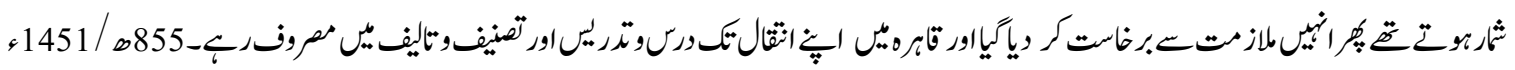

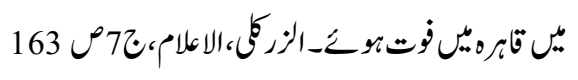


والاستحالة إلى النتن والفساد حقيقة النجاسة 21

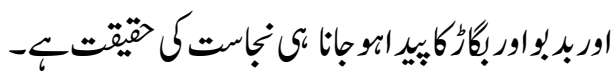
علام ططاوى

وليس إلا بالاستحالة للطيبية والاستحالة مطهرة23

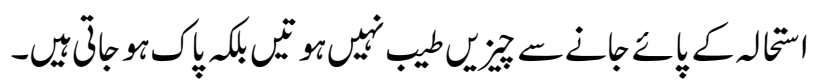

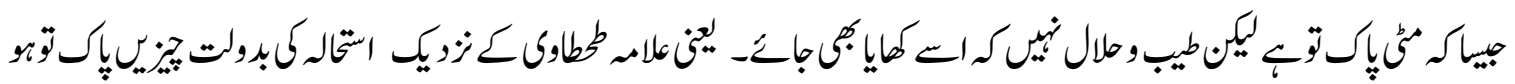

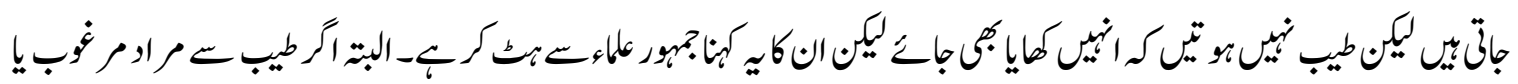

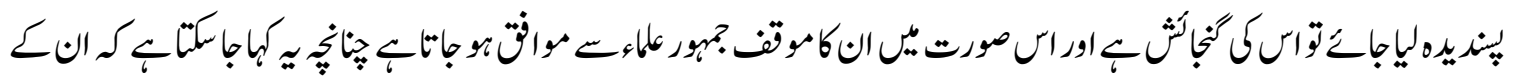

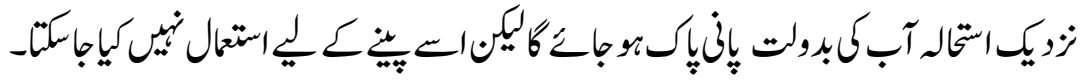

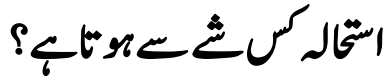

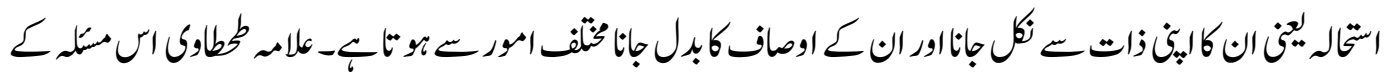

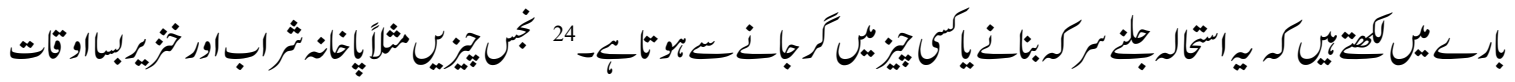

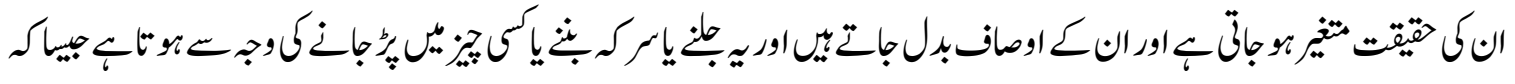

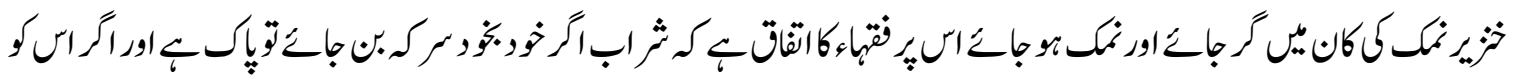

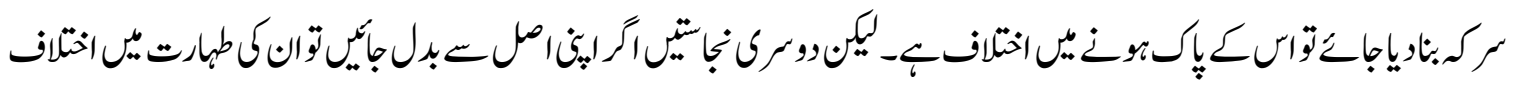

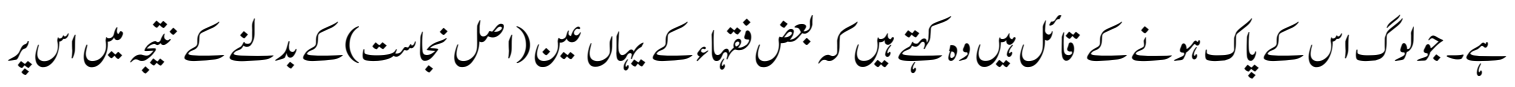

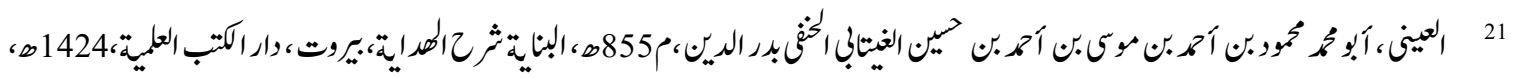
445 ص

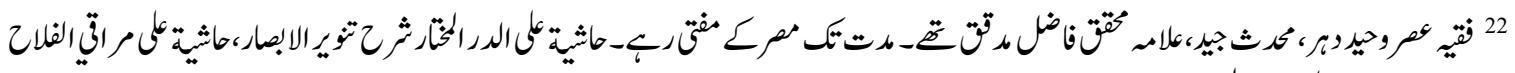

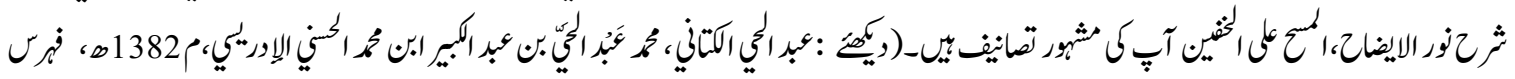

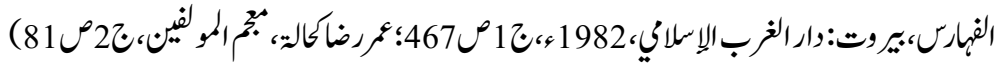

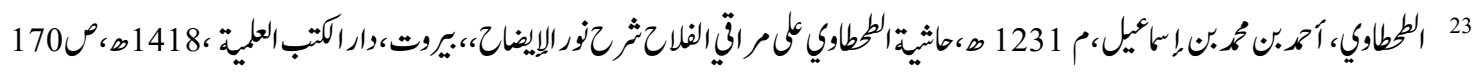
24 


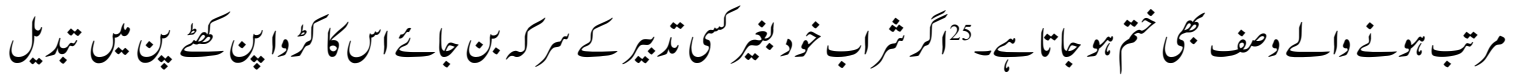

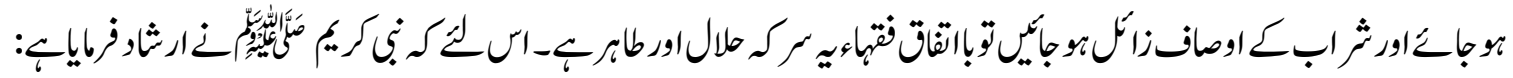

$$
\begin{aligned}
& \text { نعم الادم او الادام الخل } 26
\end{aligned}
$$

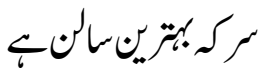

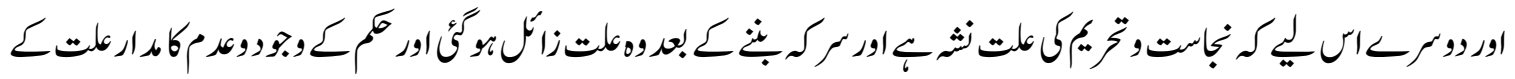

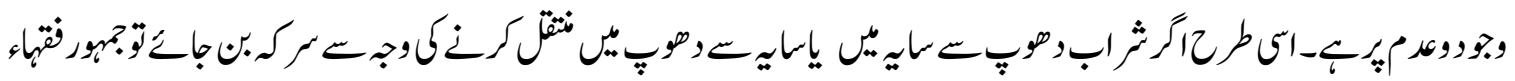

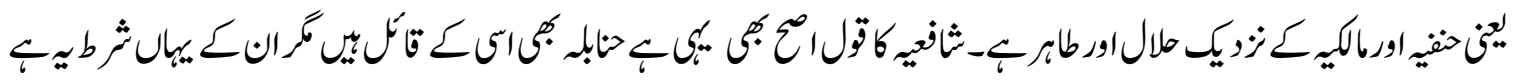

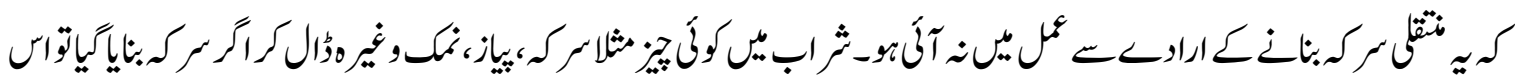

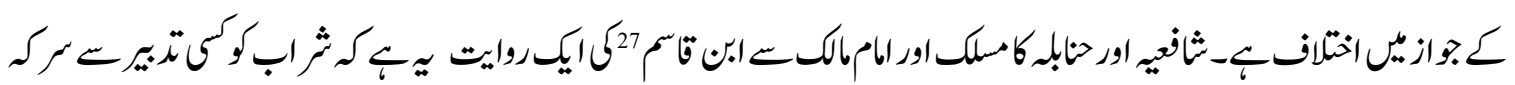

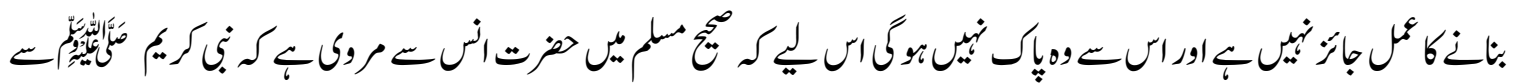

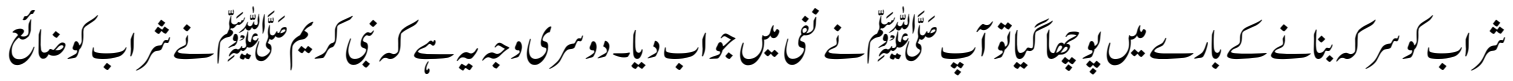

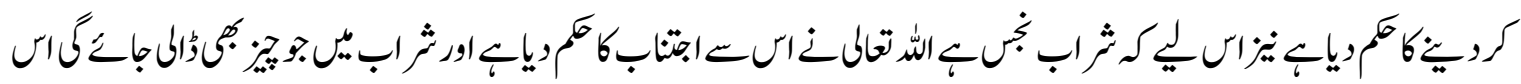

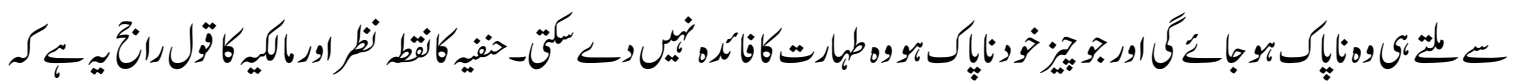

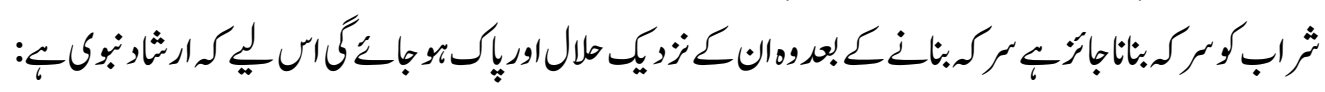
نعم الادام الخل 28

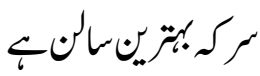

25

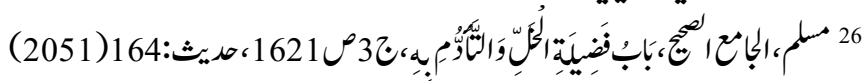

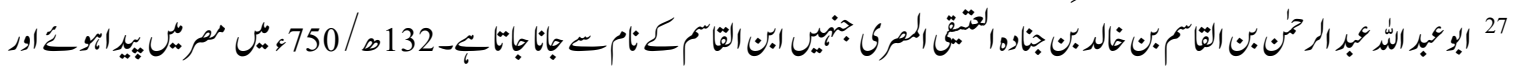

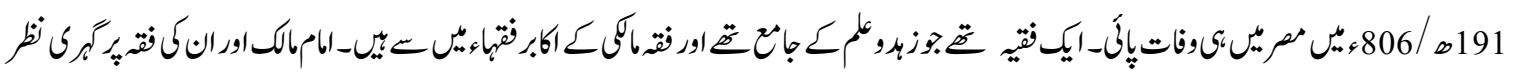

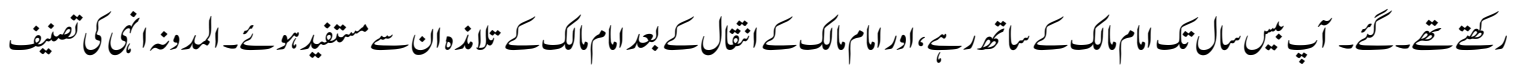

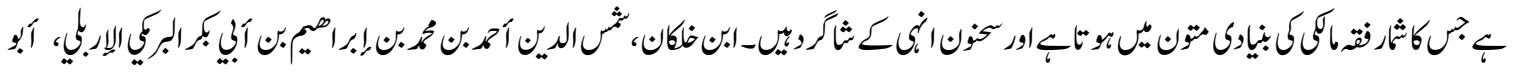

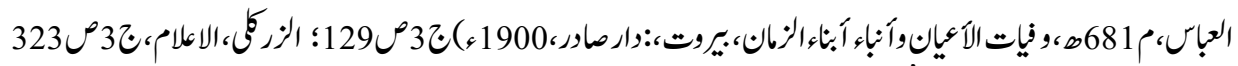

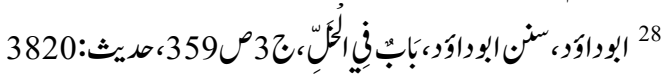




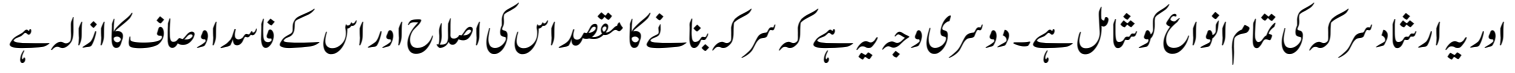

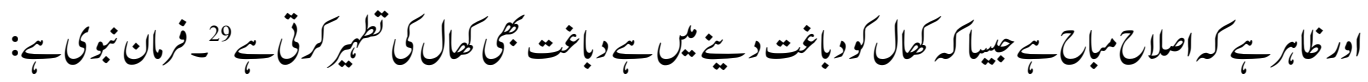

$$
\begin{aligned}
& \text { ايما إهاب دبغ فقد طهر } 30
\end{aligned}
$$

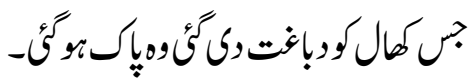

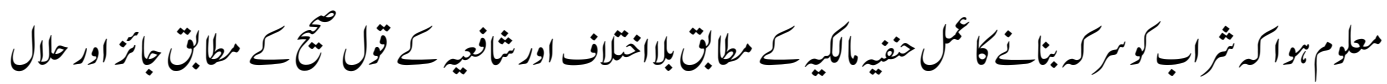

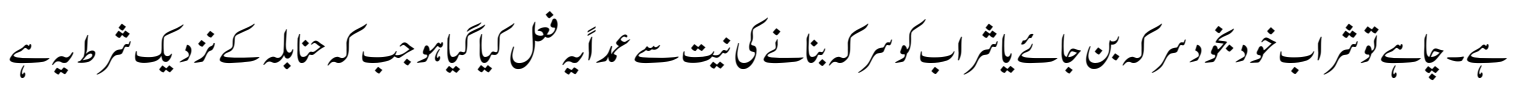

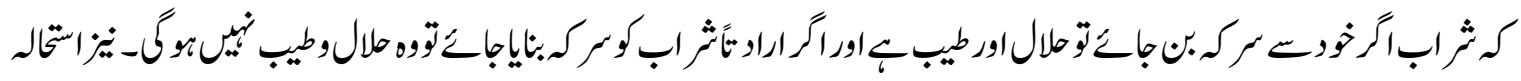

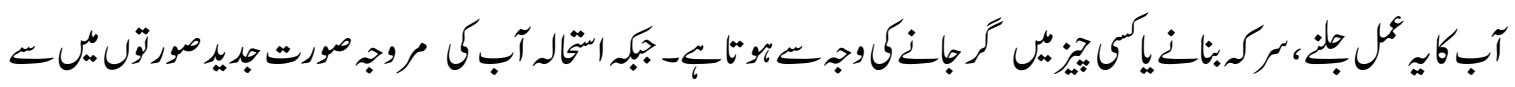

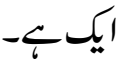

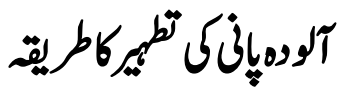

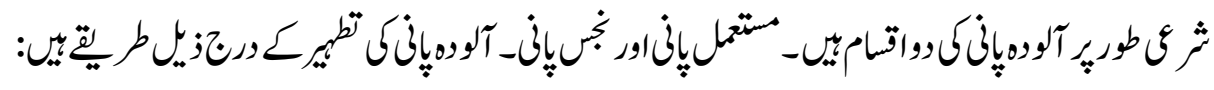

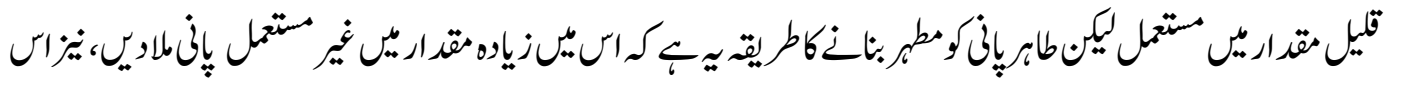

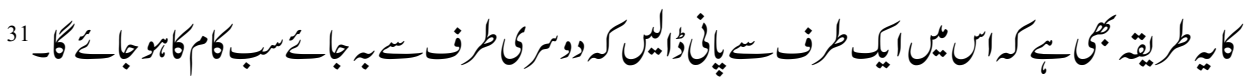

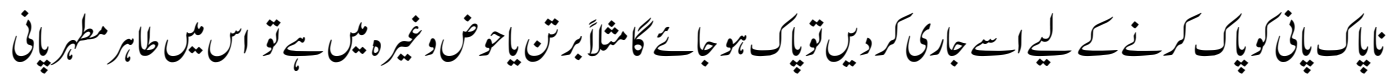

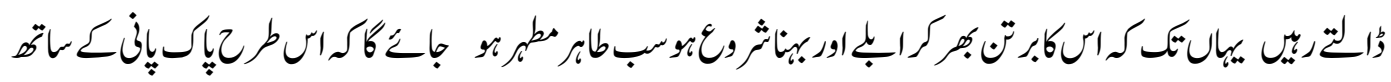

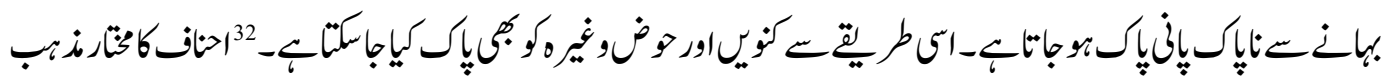

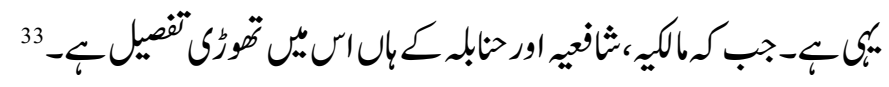

$$
29
$$

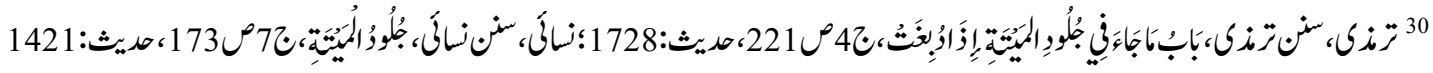

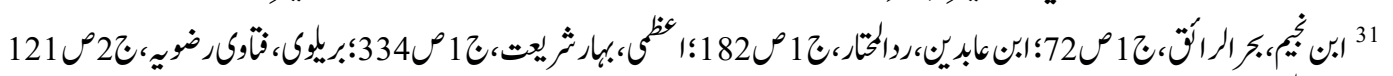

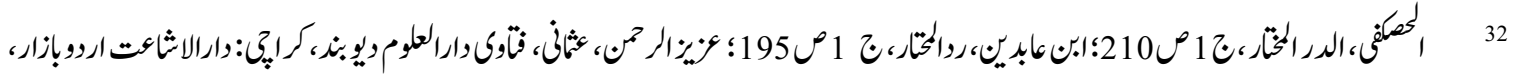

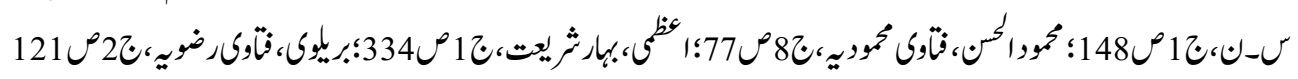
33

URL: http://alhidayah.wum.edu.pk 


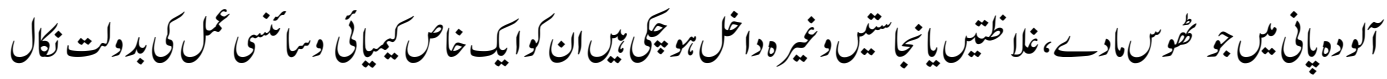

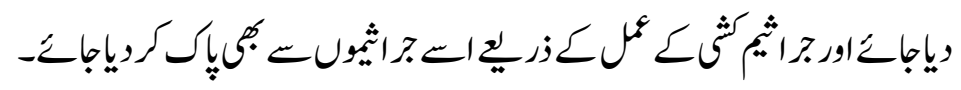

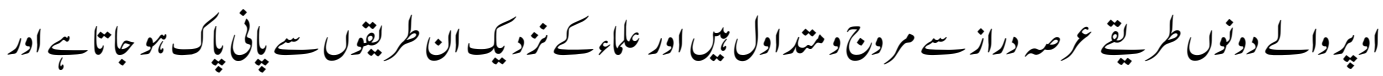

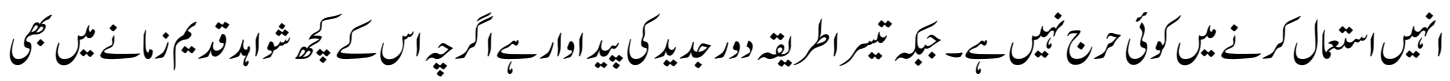

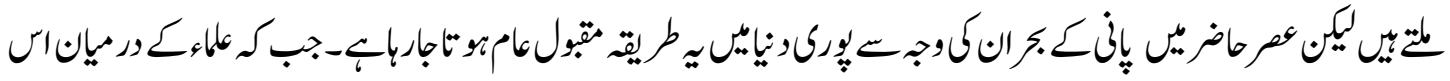

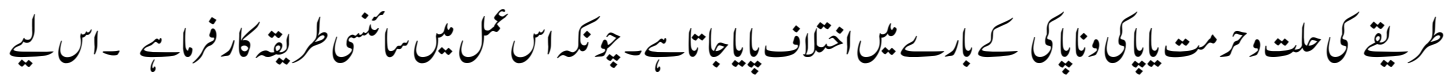

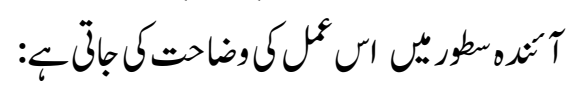

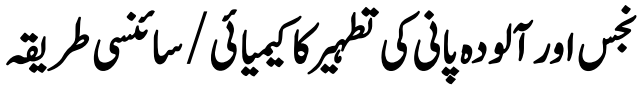

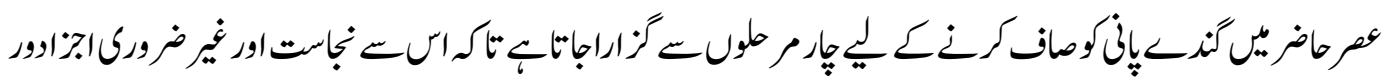

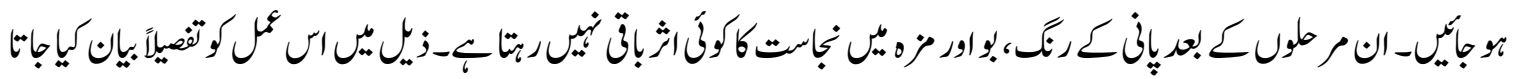

\section{مe}

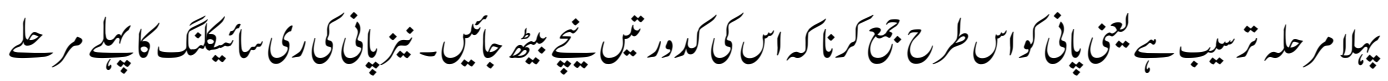

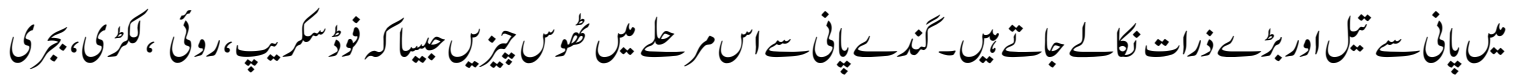

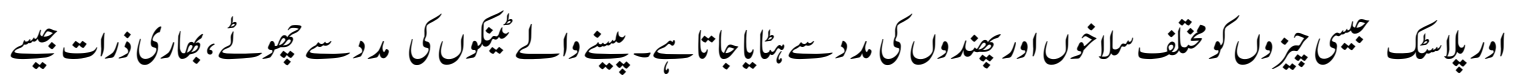

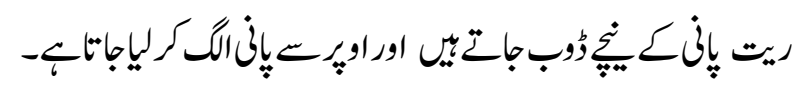

وومرام مل

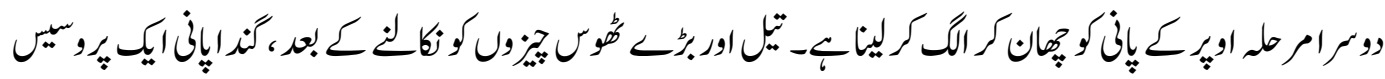

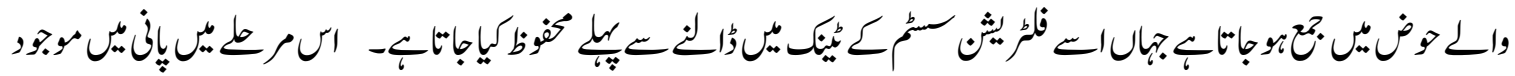

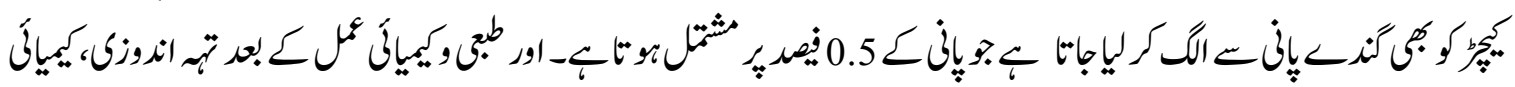

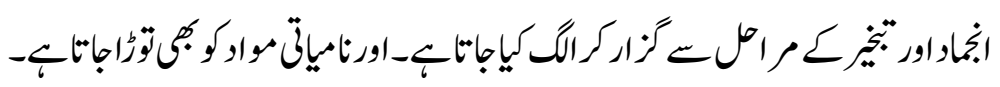

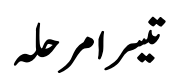

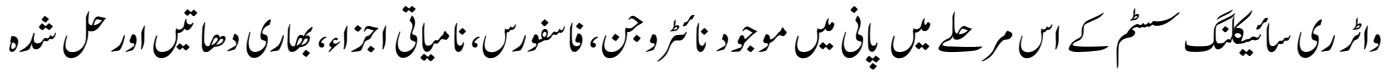

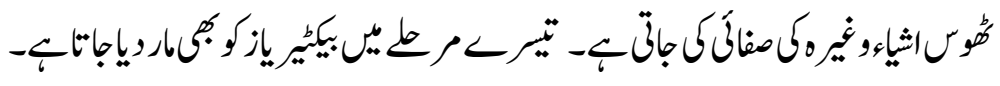




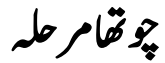

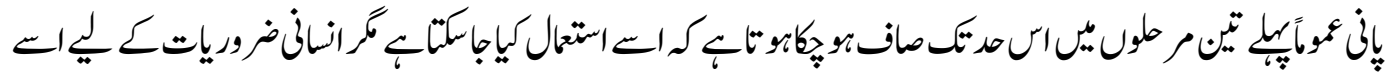

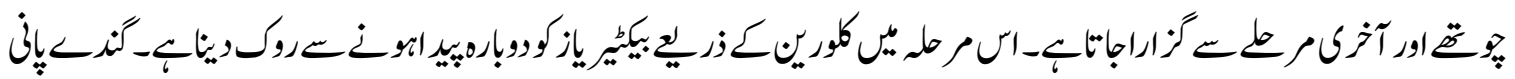

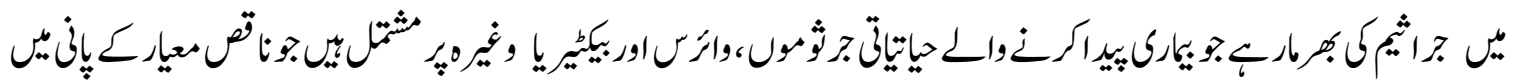

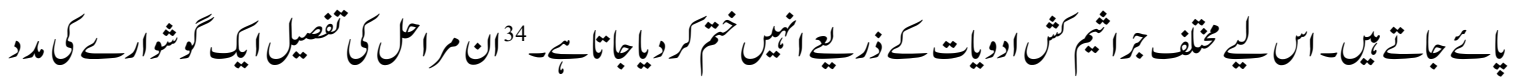

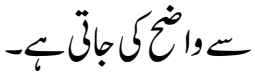

Table: Classification of common wastewater treatment processes according to their level of advancement

\begin{tabular}{|l|l|l|l|}
\hline Primary & Secondary & Tertiary & Advanced \\
\hline Bar or Bow Screen & Activated Sludge & Nitrification & Chemical treatment \\
\hline Grit Removal & Extended aeration & Denitrification & Reverse osmosis \\
\hline Primary Sedimentation & Aerated lagoon & Chemical precipitation & Electrodialysis \\
\hline Comminution 9 & Trickling filter & Disinfection & Carbon adsorption \\
\hline Oil/flat removal & Rotating bio-discs & (Direct) filtration & Selective icon exchange \\
\hline Flow equalisation & $\begin{array}{l}\text { Anaerobic } \\
\text { treatment/UASB }\end{array}$ & Chemical oxidation & Hyperfiltration \\
\hline pH neutralization & Anaerobic Filter & Biological p removal & Oxidation \\
\hline Imhoff tank & Stablisation ponds & Constructed wetlands & Detoxification \\
\hline & Constructed wetlands & Aquaculture & \\
\hline & Aquaculture & & \\
\hline
\end{tabular}

Source: Richard Helmer and Ivanildo Hespanhol, Water Pollution Control-A Guide to the use of Water Quality Management Principles. p.62.

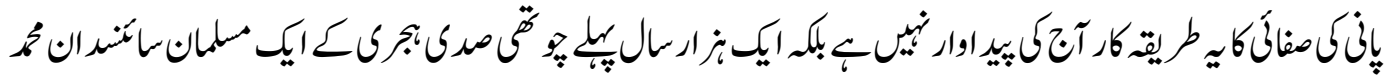

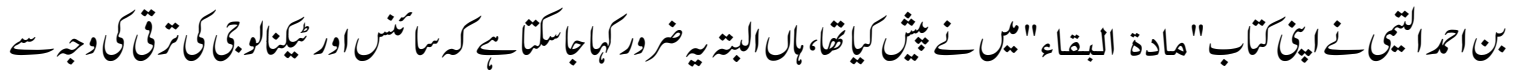

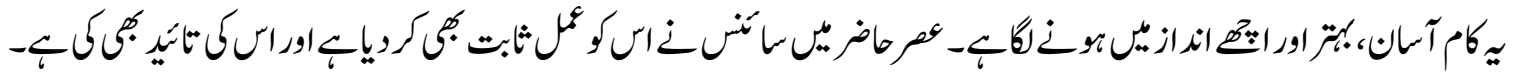

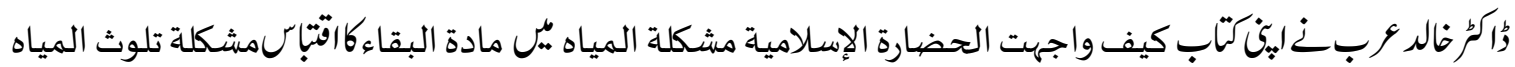

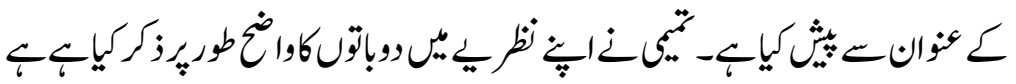

$$
\begin{aligned}
& \text { (1) }
\end{aligned}
$$

${ }^{34}$ Richard Helmer and Ivanildo Hespanhol, Water Pollution Control-A Guide to the use of Water Quality Management Principles, (London: E\&FN Spon an imprint of Thomson Professional,N.D.) p.62. 


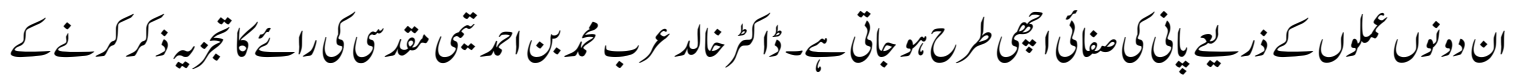

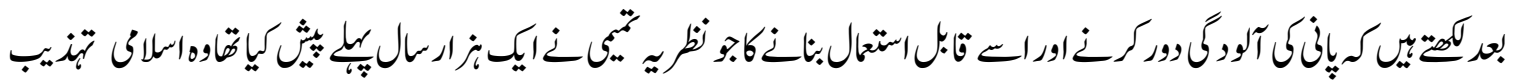

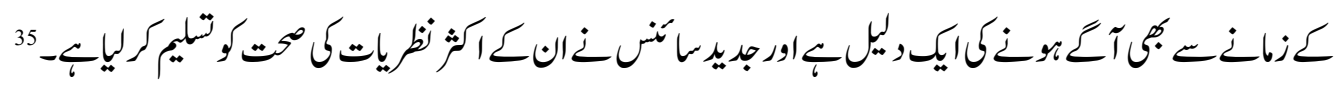

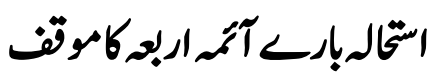

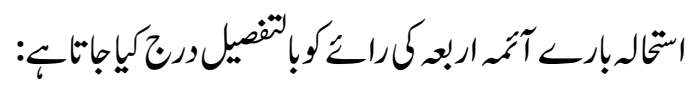

\section{كالكيكاموَتف}

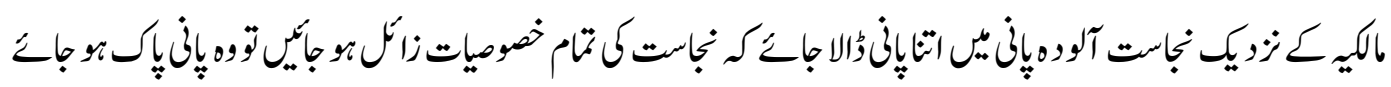

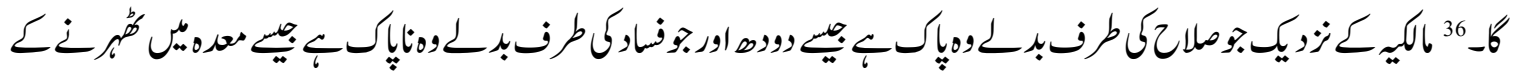

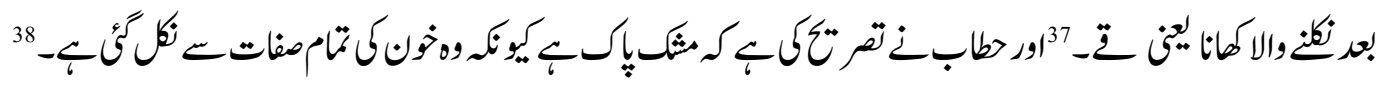

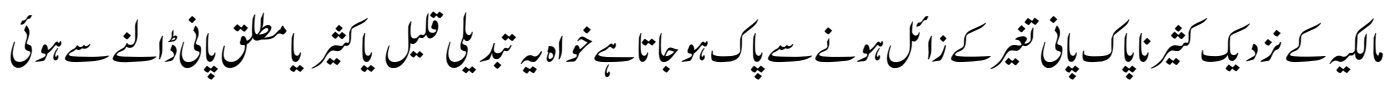

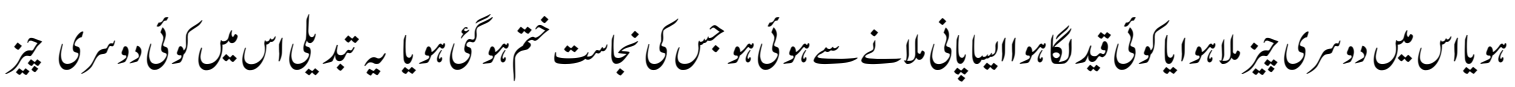

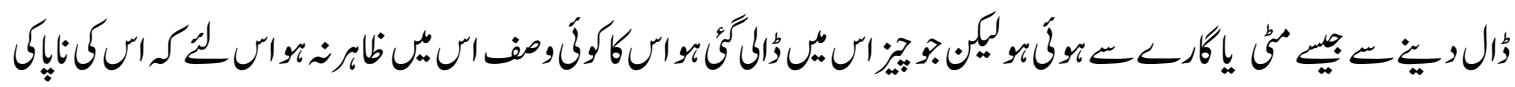

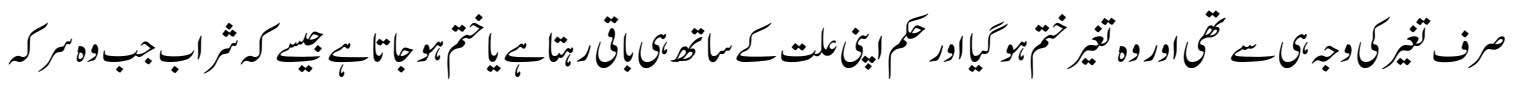

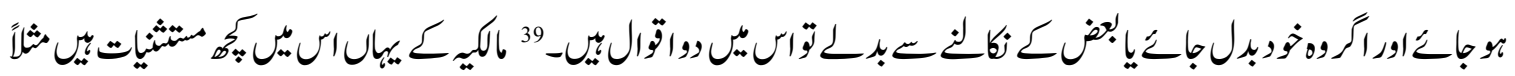

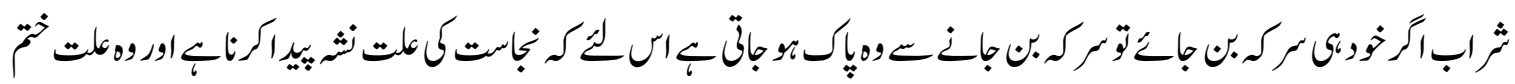

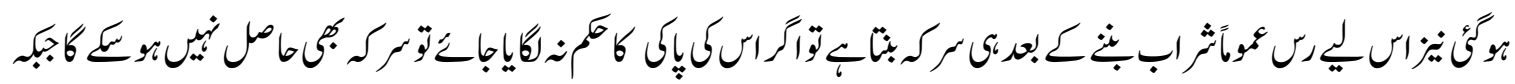

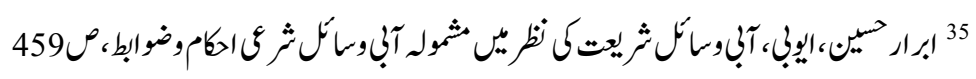

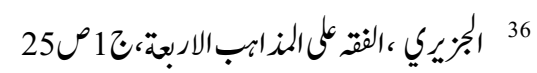

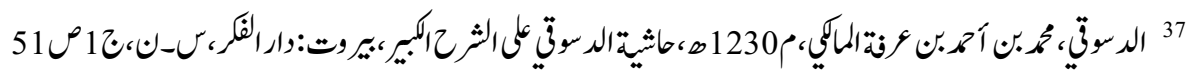
38

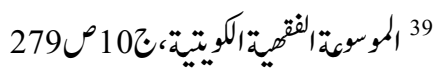




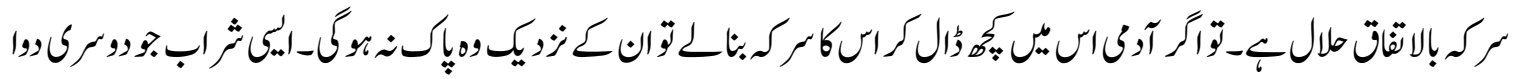

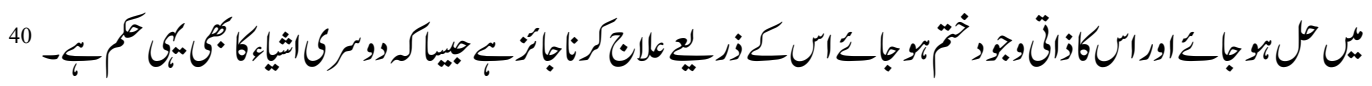

ثوافع كموقتف

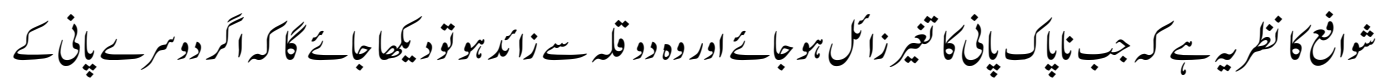

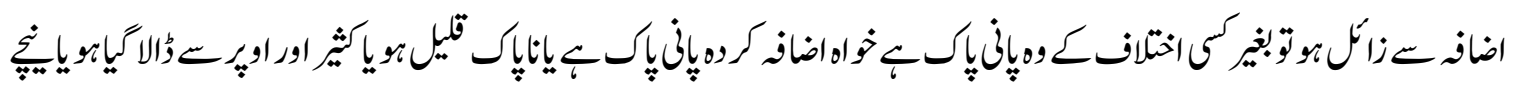

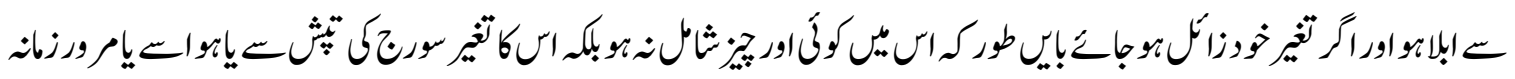

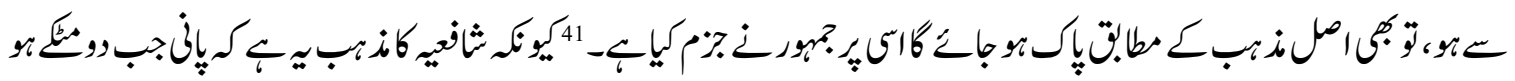

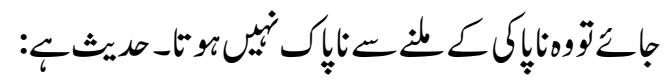

$$
\begin{aligned}
& \text { اذا كان الماء قلتين لم يحمل الخبث4 }
\end{aligned}
$$

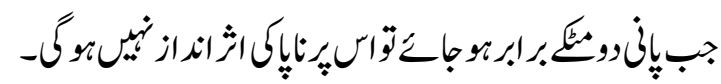

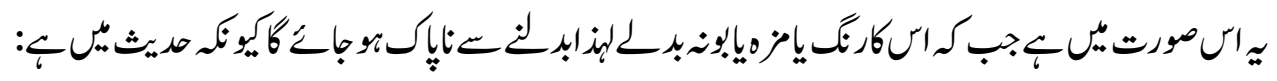

$$
\begin{aligned}
& \text { ان الماء طهور لا ينجسه شىء إلا ما غير لونه أو طعمه أو ريحه4 } 43
\end{aligned}
$$

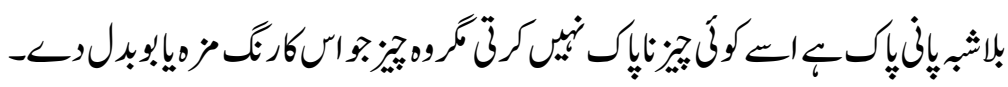

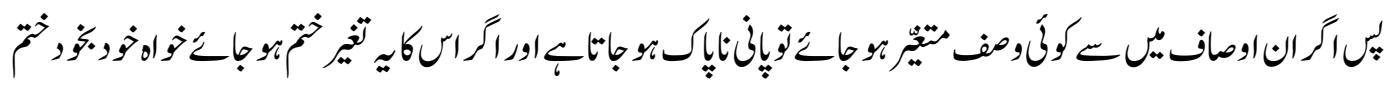

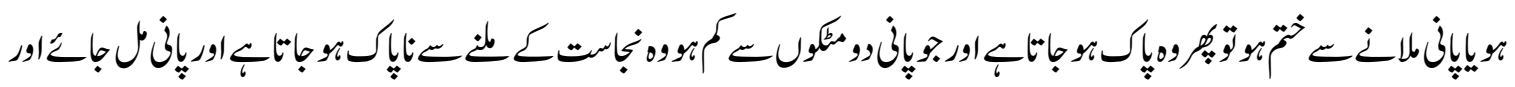

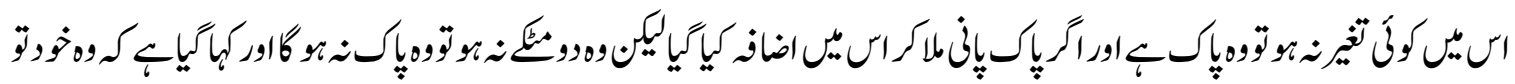

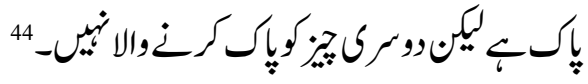

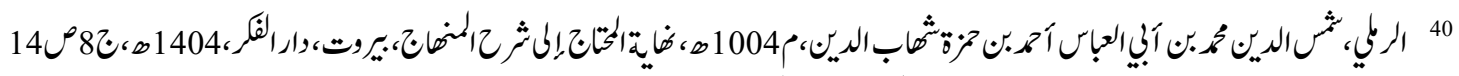

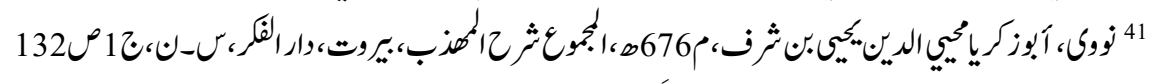

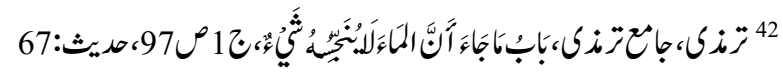

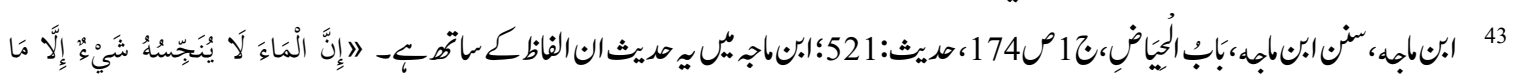

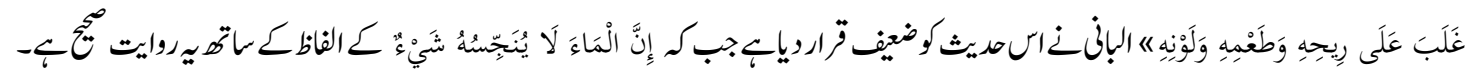

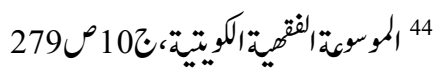




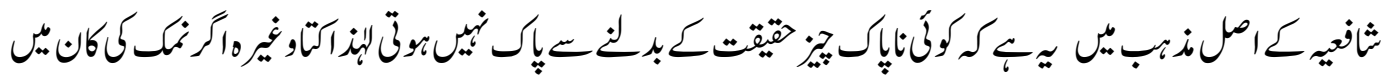

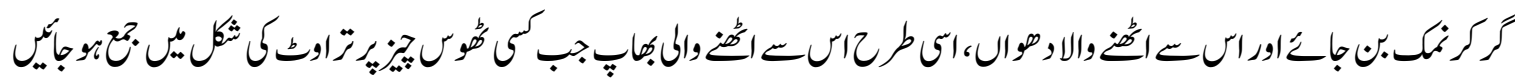

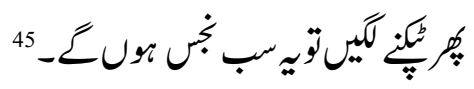

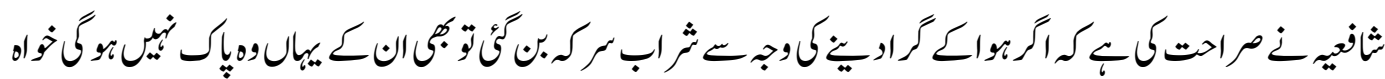

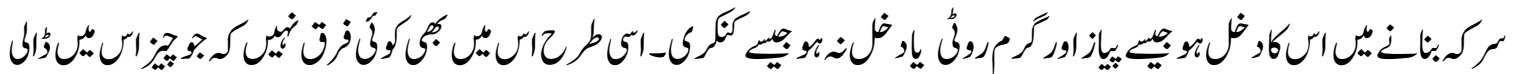

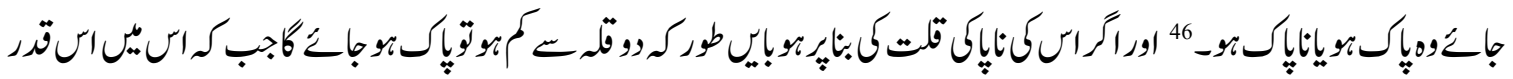

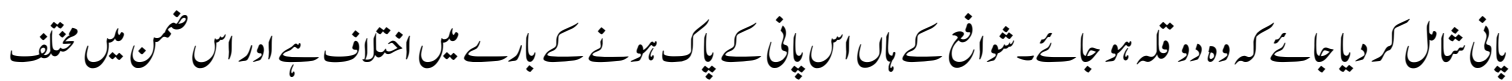

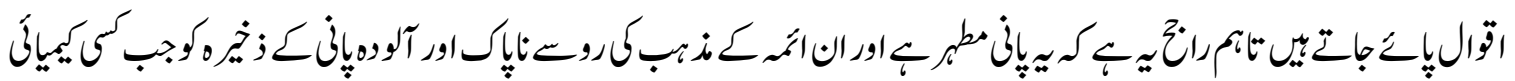

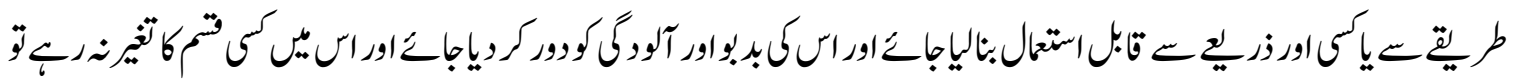

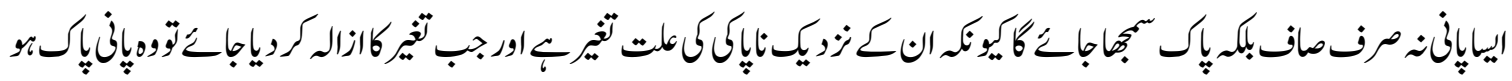

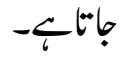

\section{حنابلم كاموَّف}

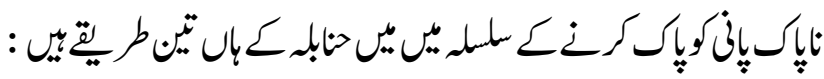

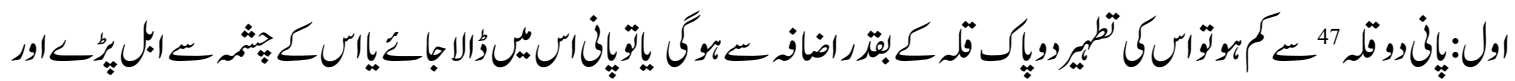

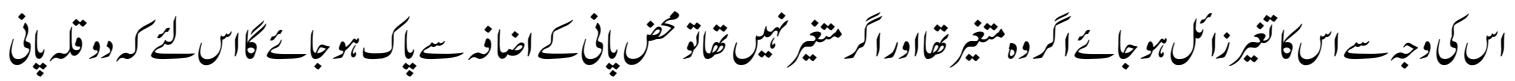

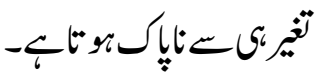

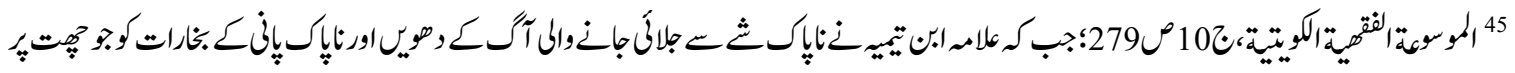

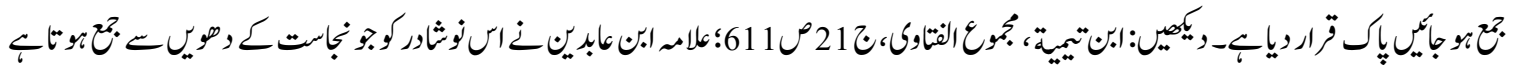

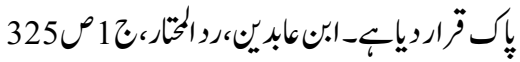
279100

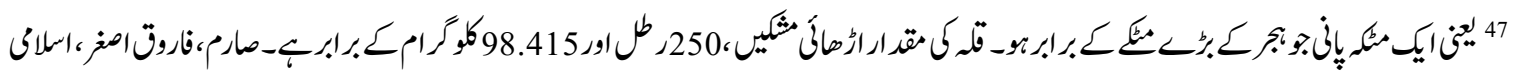

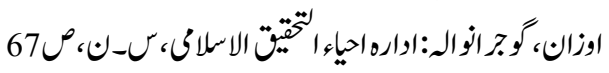




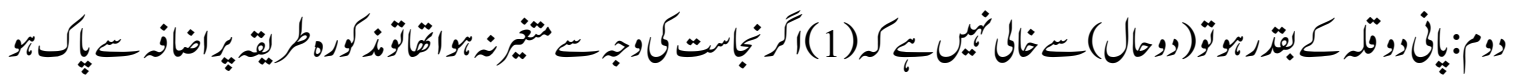

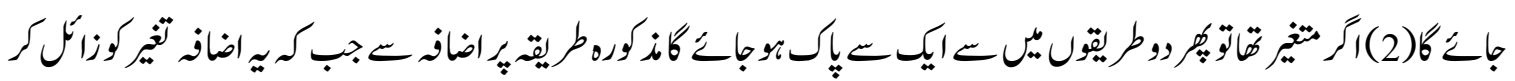

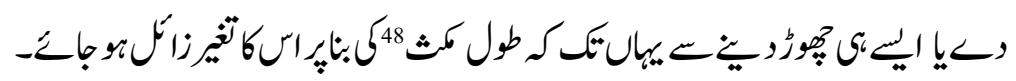

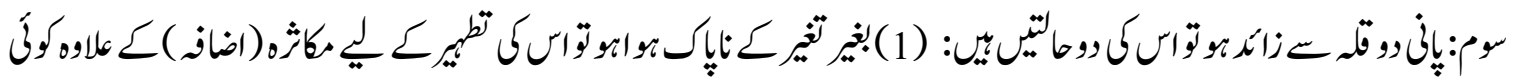

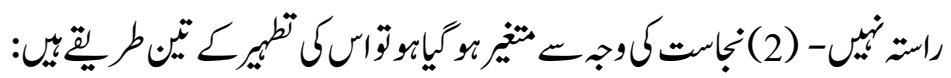

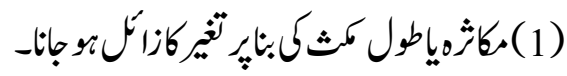

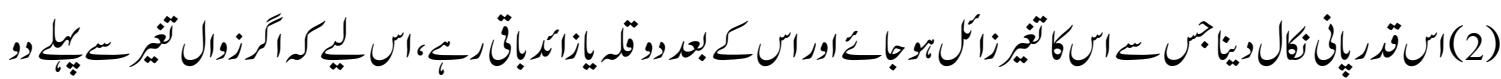

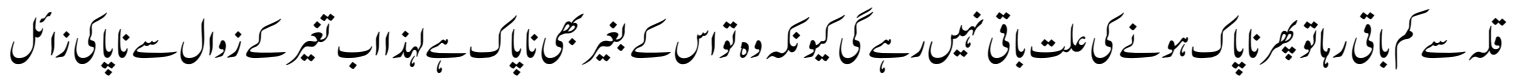

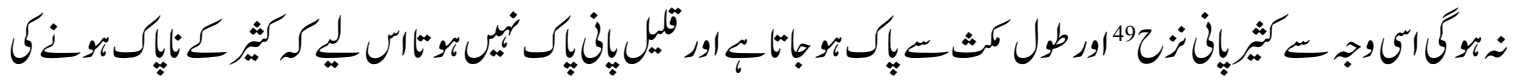

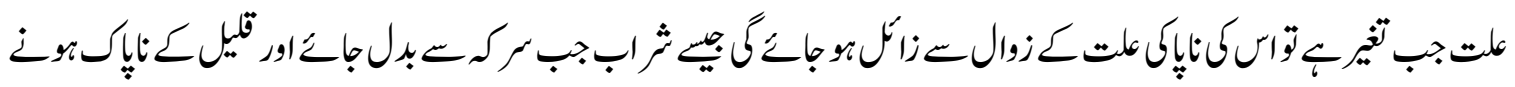

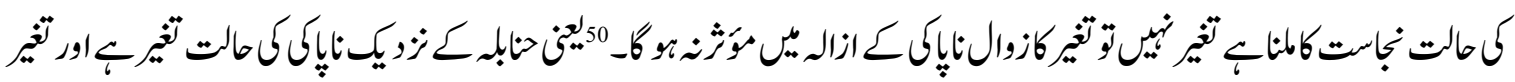

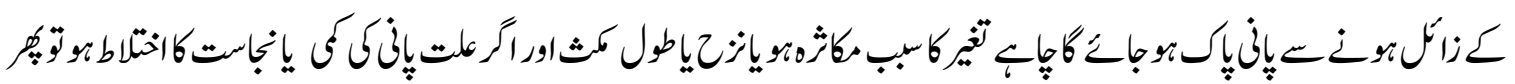

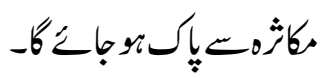

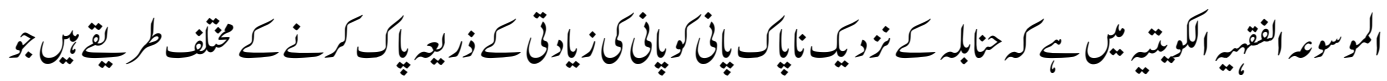

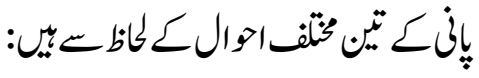

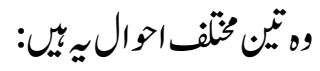

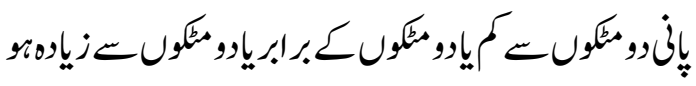

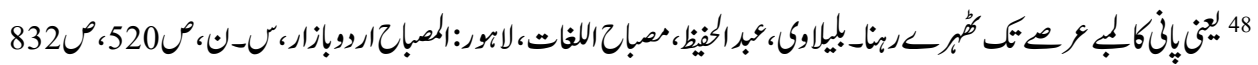

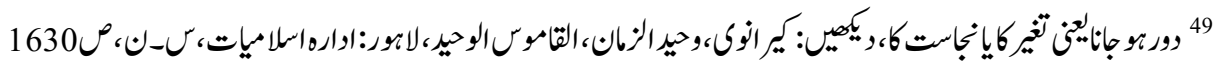

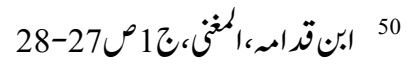




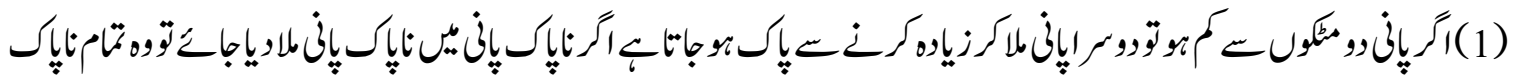

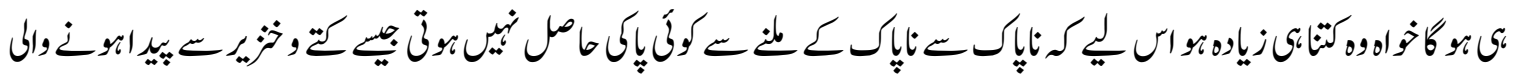

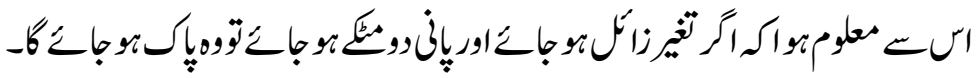

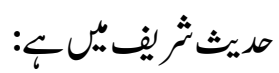

اذا بلغ الماء قلتين لم يحمل الخبث 51

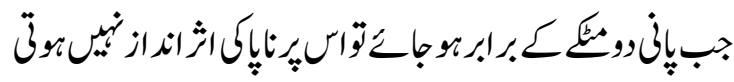

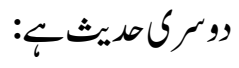

ان الماء طهور لا ينجسه شيء إلا ما غير لونه أو طعمه أو ريحه 52

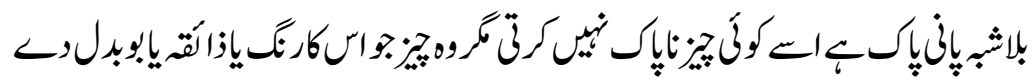

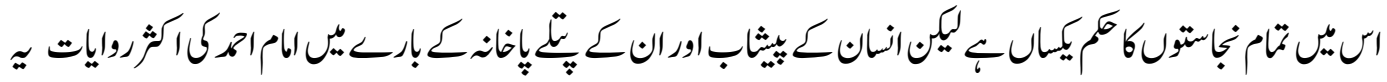

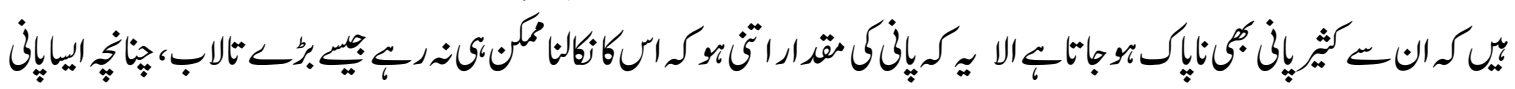
كمنيز

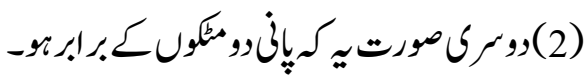

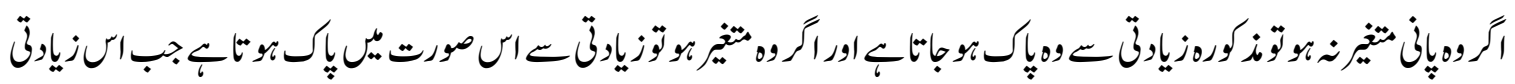

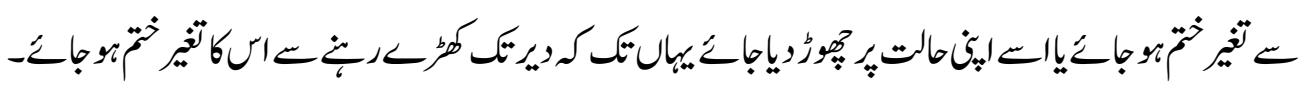

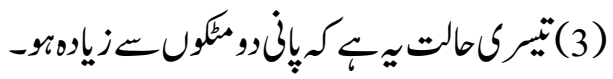

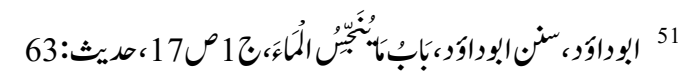

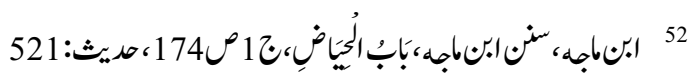




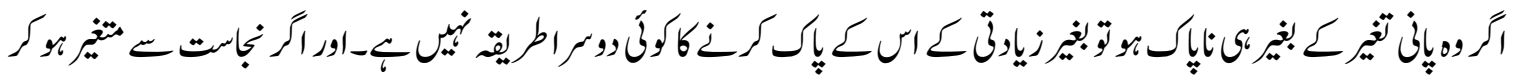

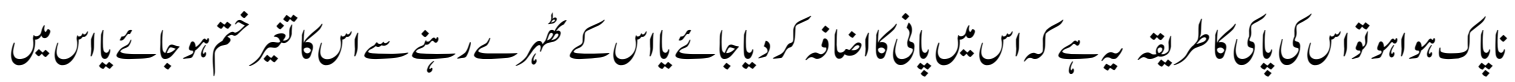

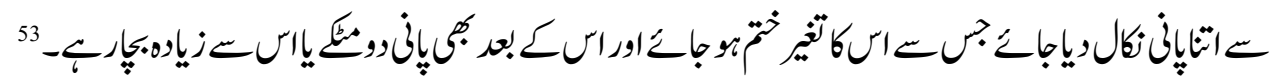

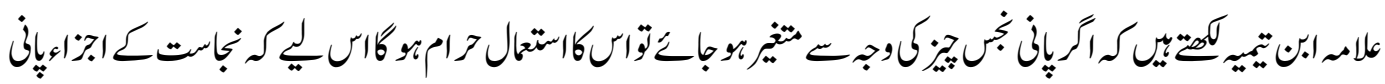

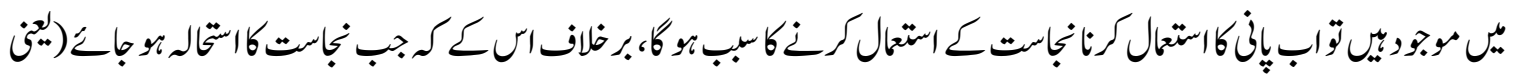

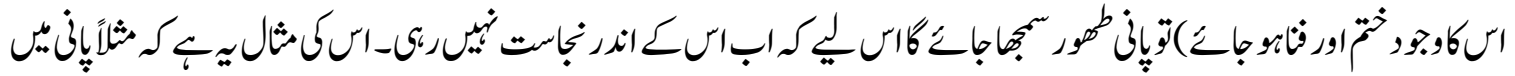

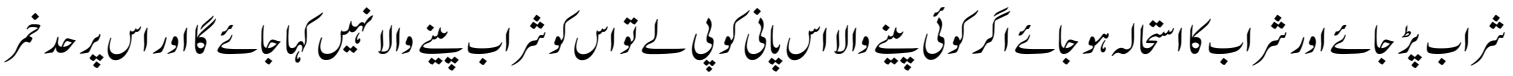

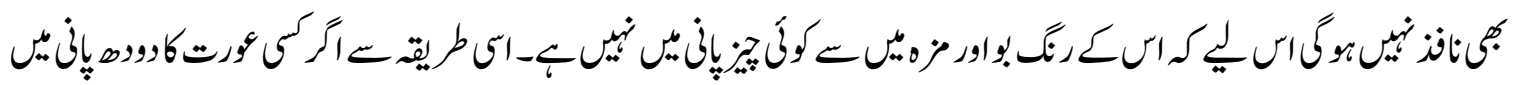

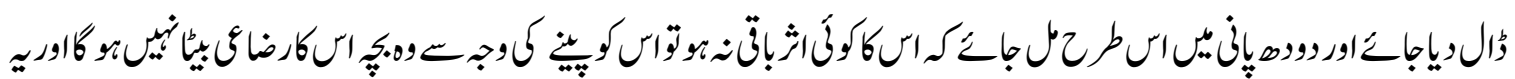

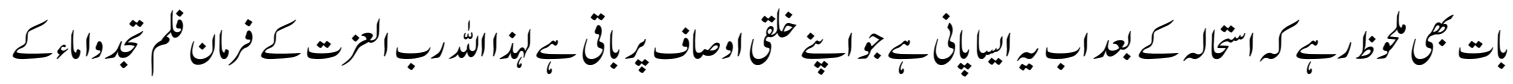

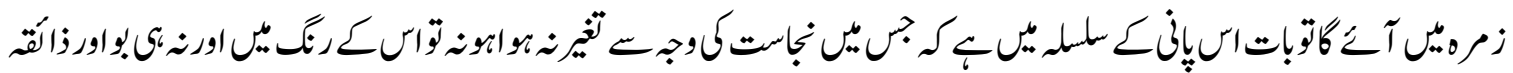

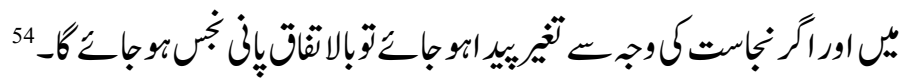

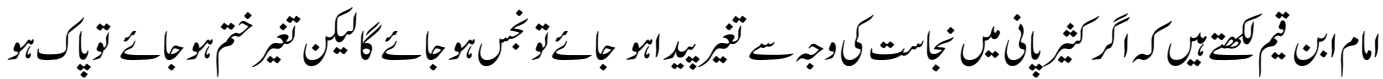

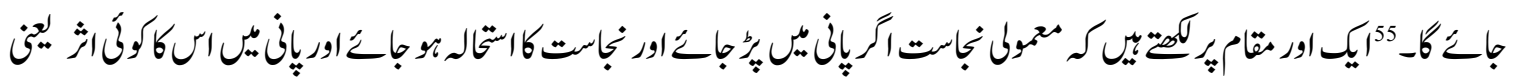

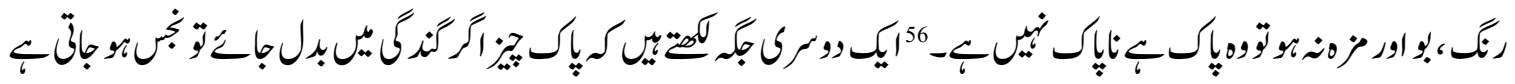

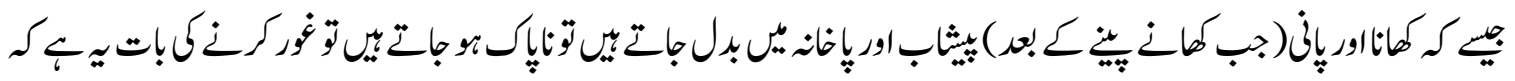

27910033

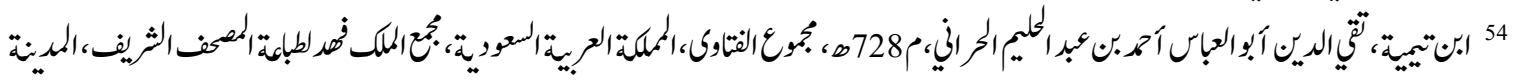

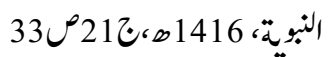

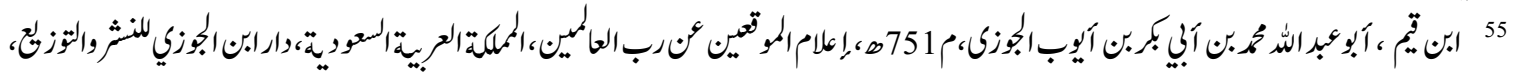
2960120 56 
ALHIDÄYAH

(Vol. 3 No. 1, 2021)

ISSN(Print): 2707-7454 | ISSN(Online): 2788-7537

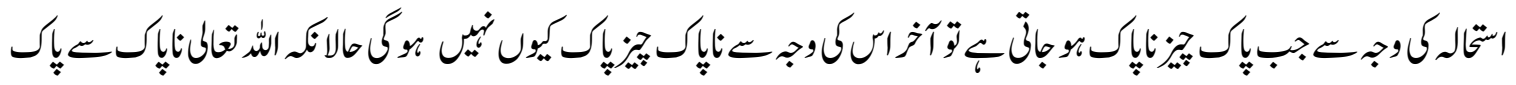

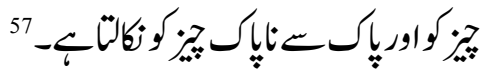

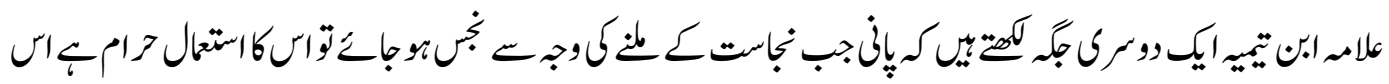

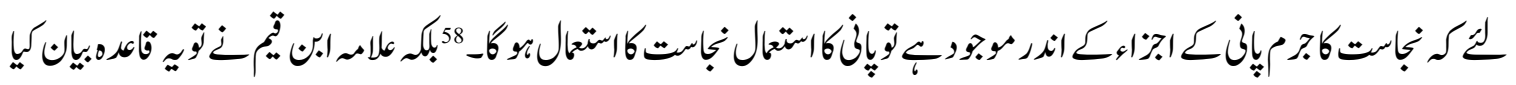

$:$

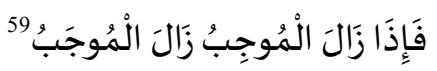

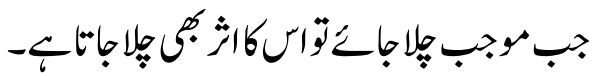

احنافكموَقف

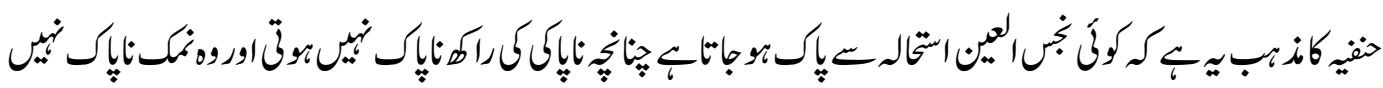

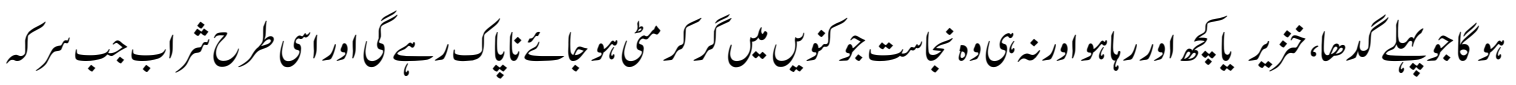

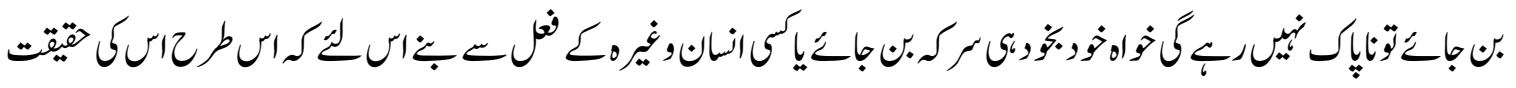

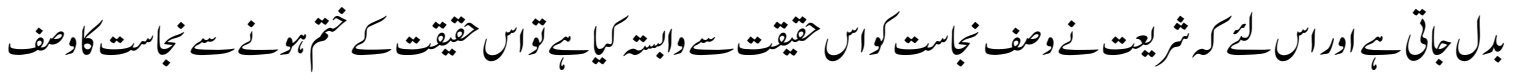

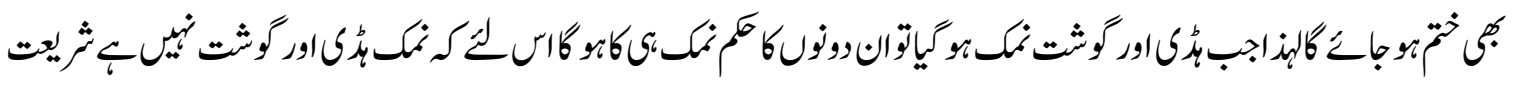

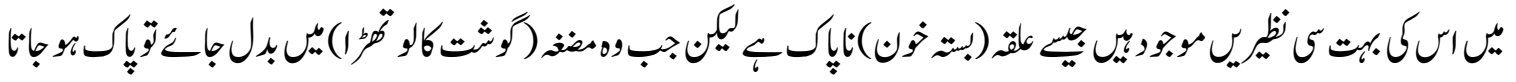

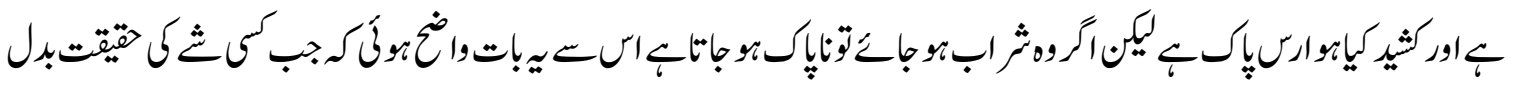

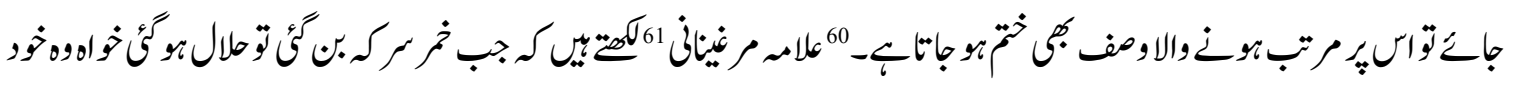

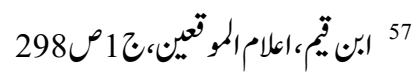

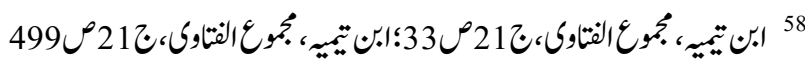

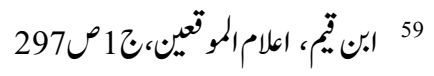
60

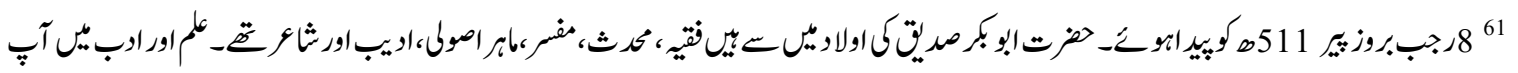

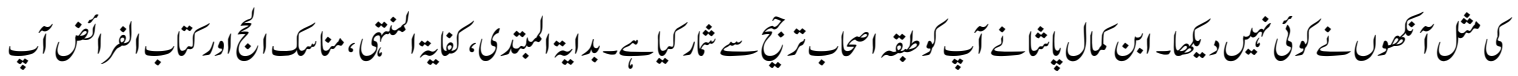

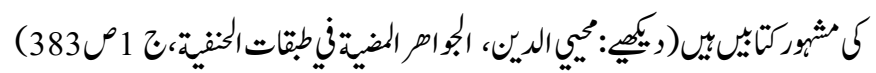

17

URL: http://alhidayah.wum.edu.pk 


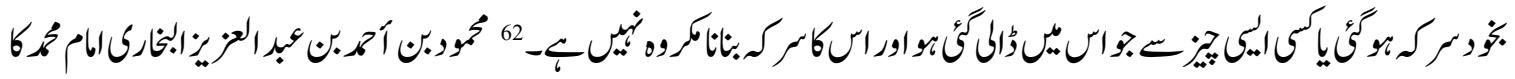

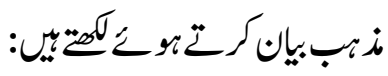

فالمذهب عند محمد رحمه الله أن النجس يطهر بالتغيير والاستحالة، خلافاً لأبي يوسف رحمه الله.63.

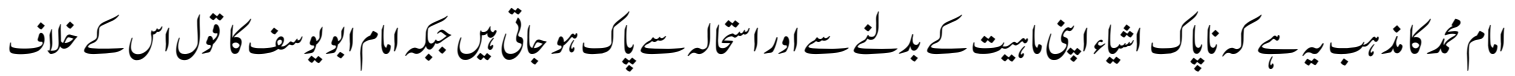

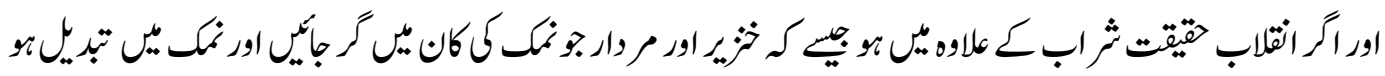

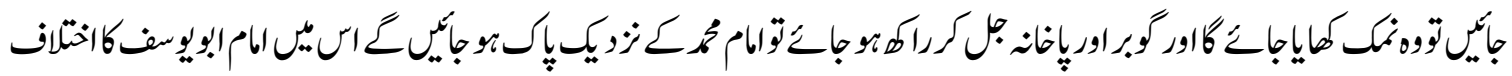

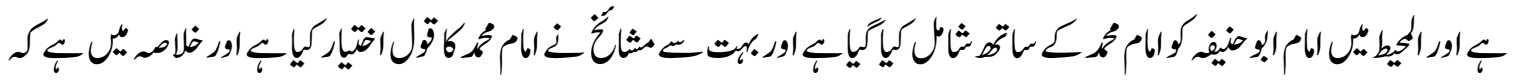

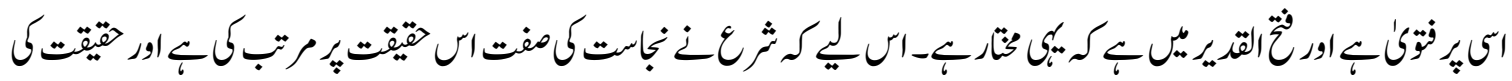

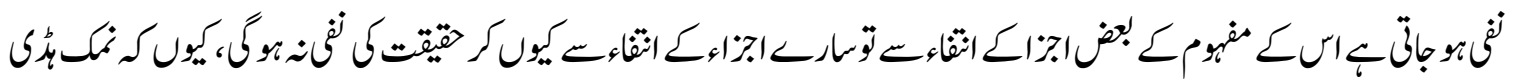

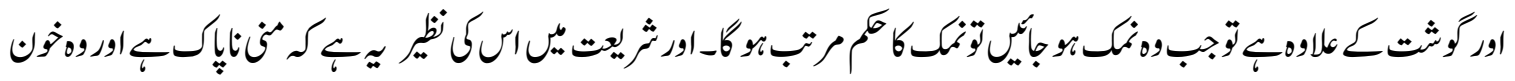

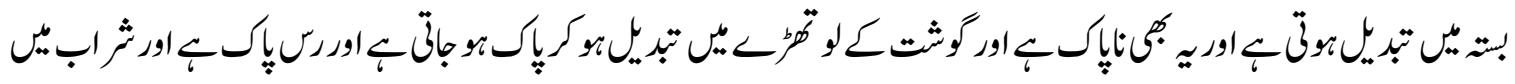

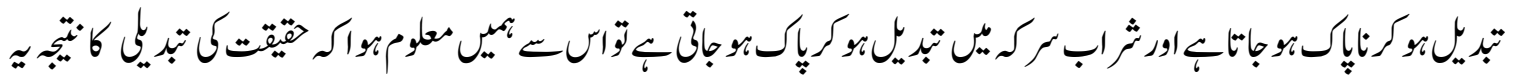

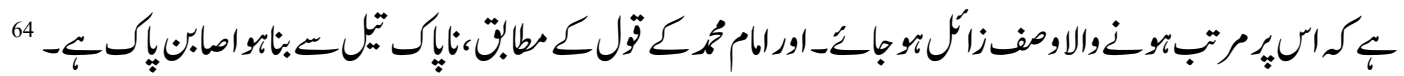

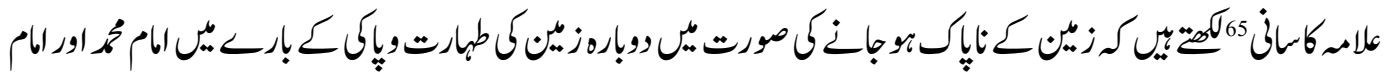

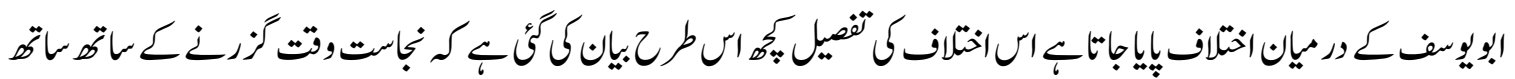

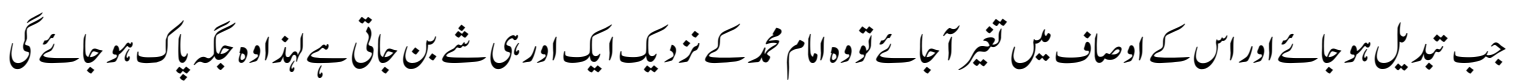

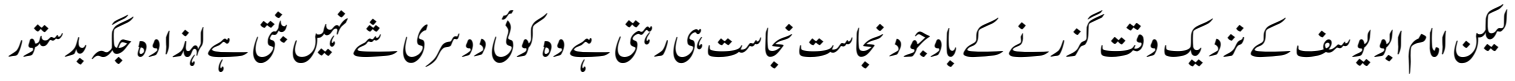

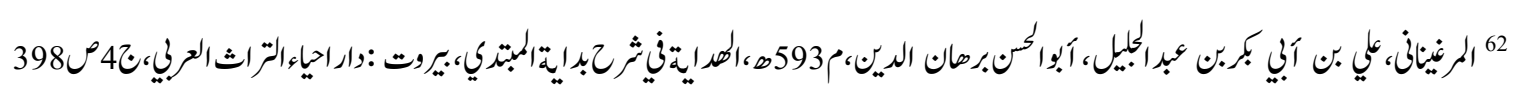

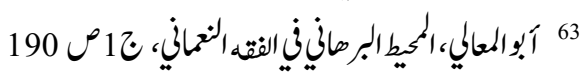
239

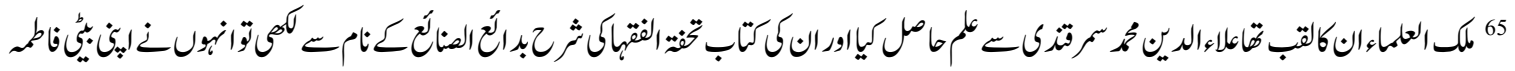

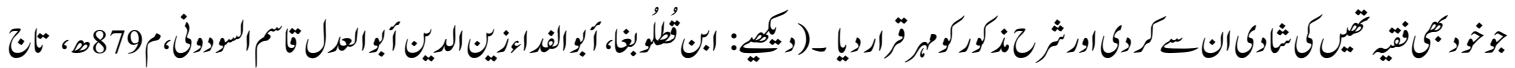

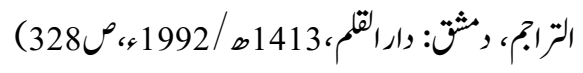




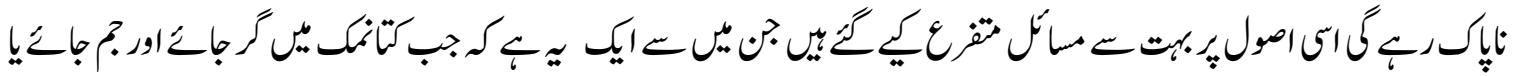

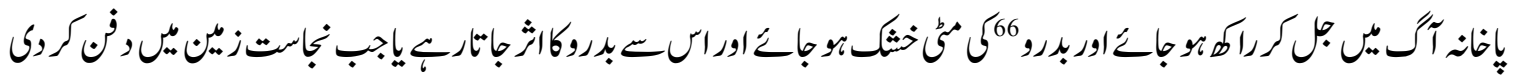

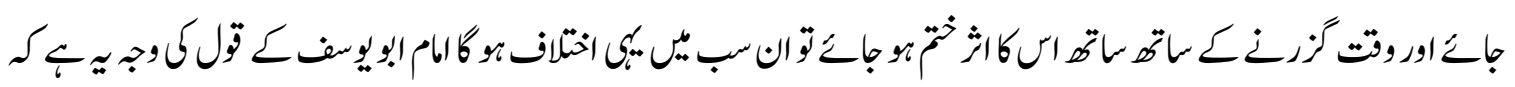

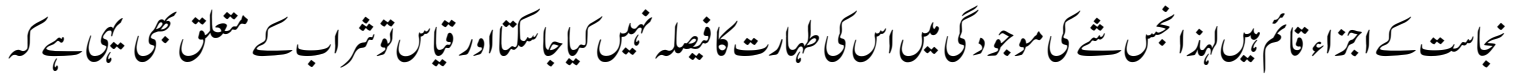

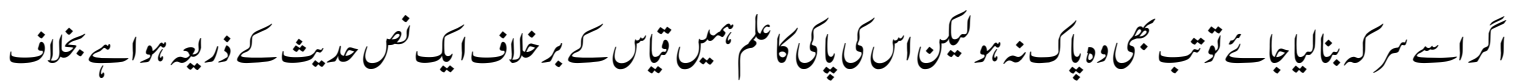

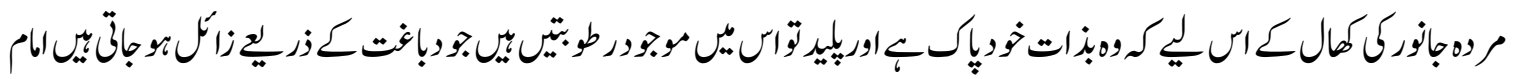

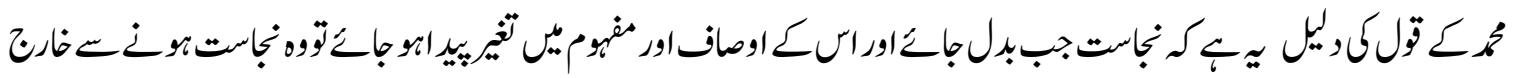

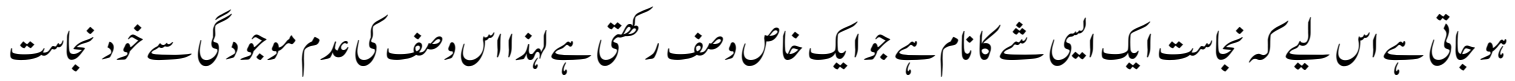

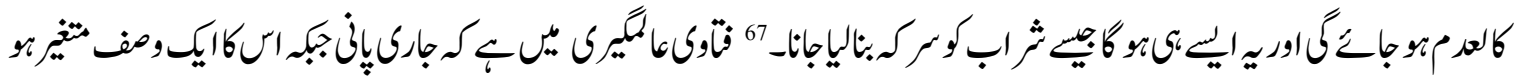

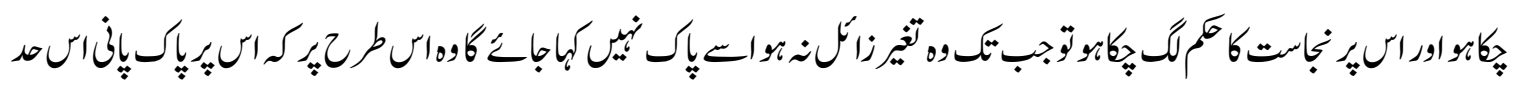

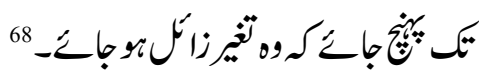

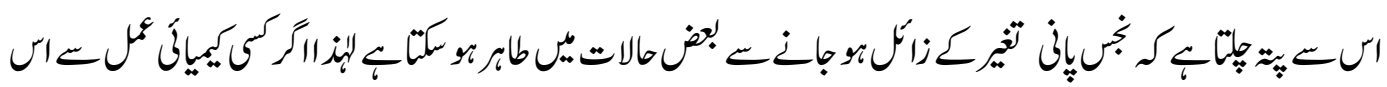

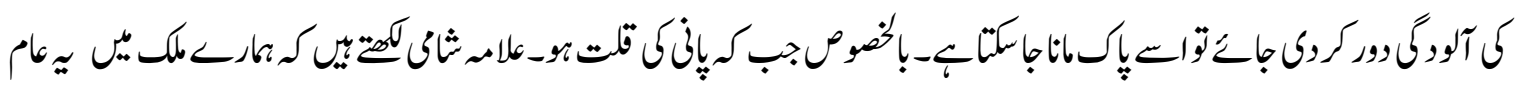

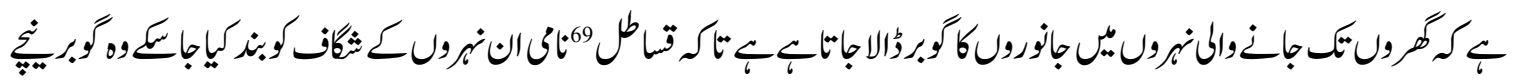

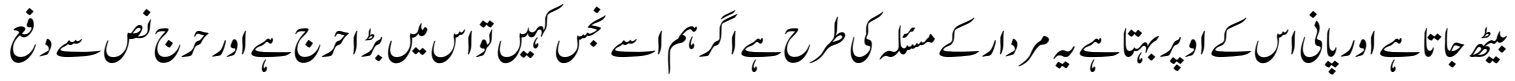
كيآياك-ب

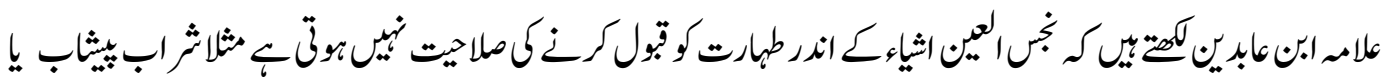

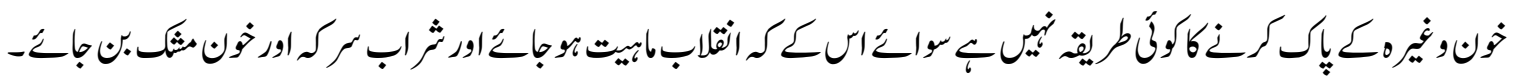

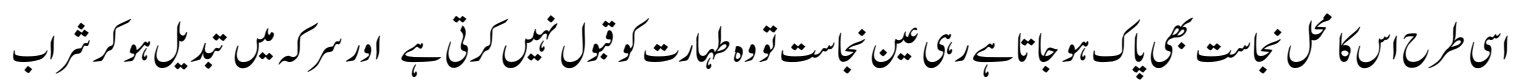

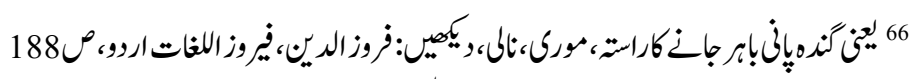

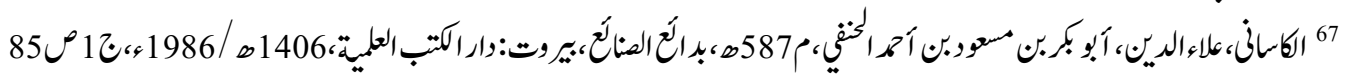
188

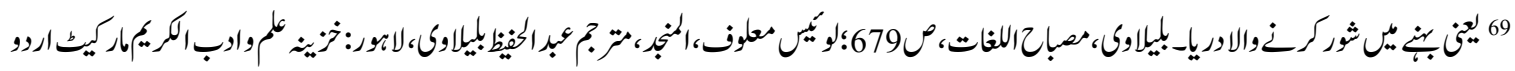

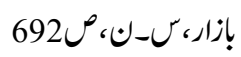

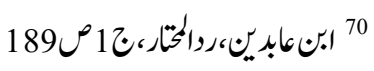




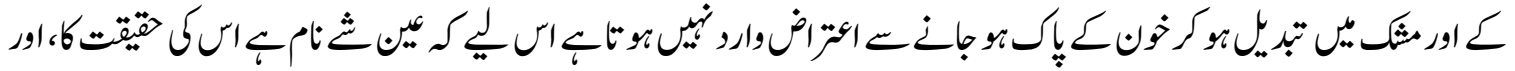

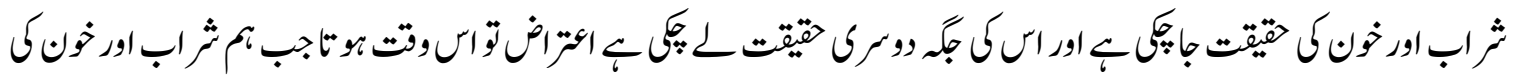

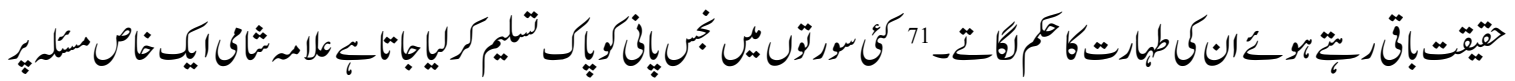

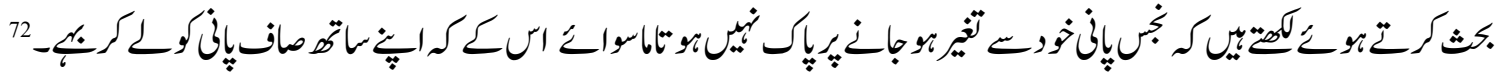

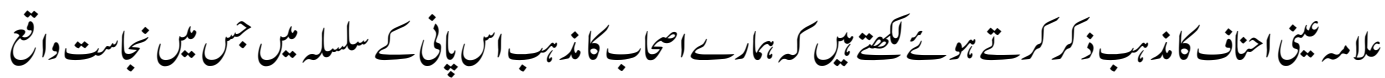

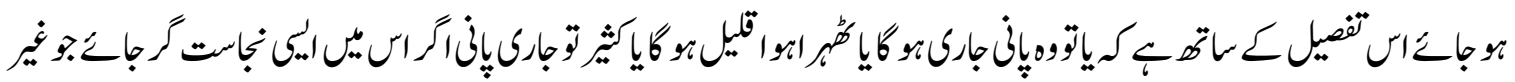

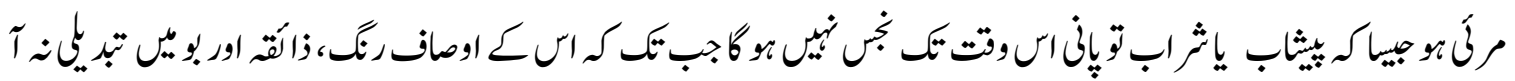

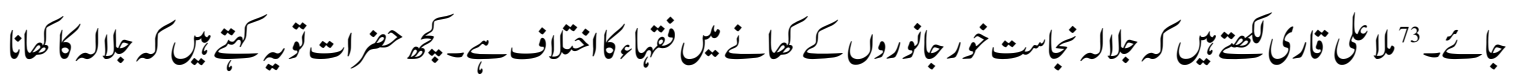

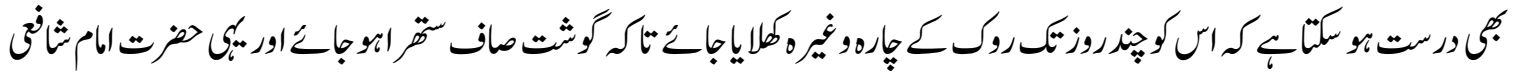

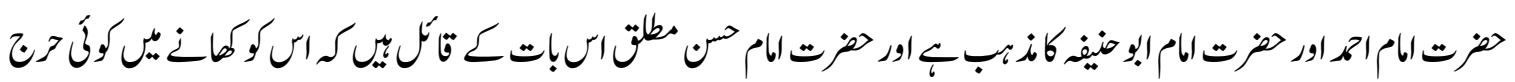

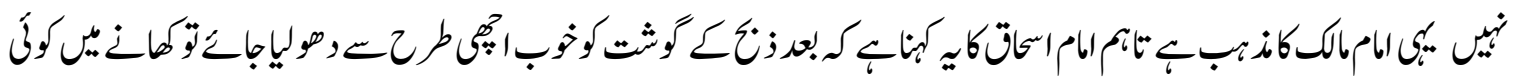

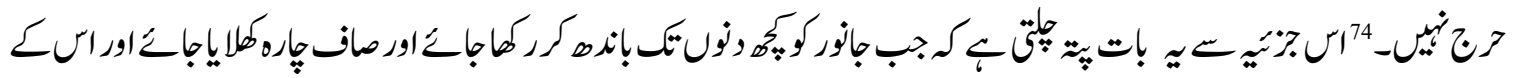

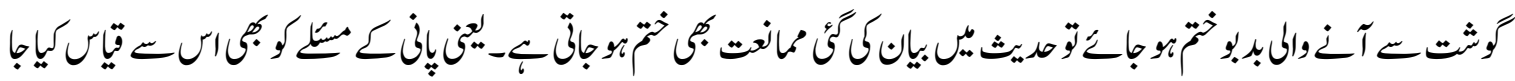

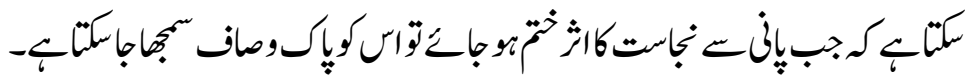

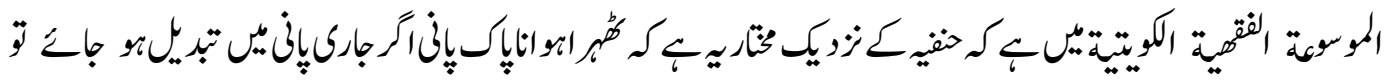

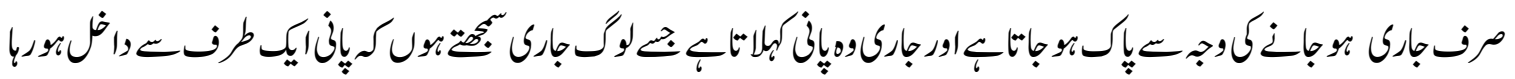

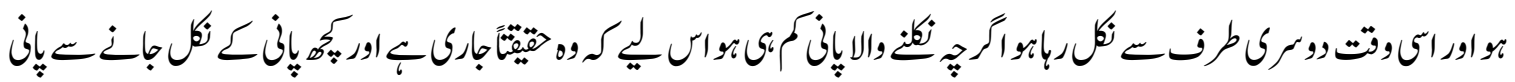

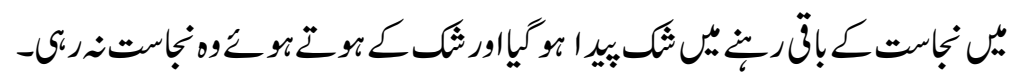

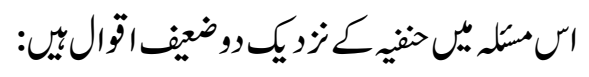

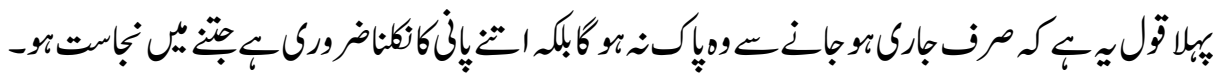

11

72

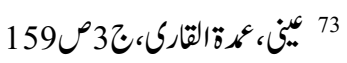

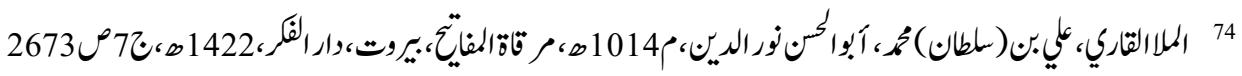




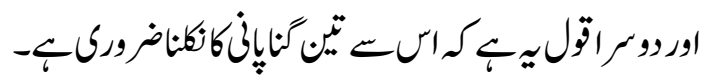

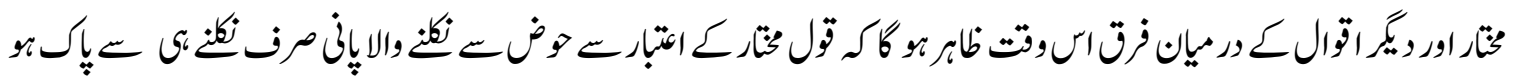

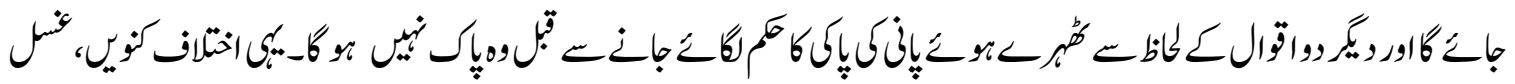

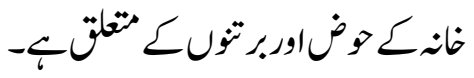

\section{طابريمكامؤقنف}

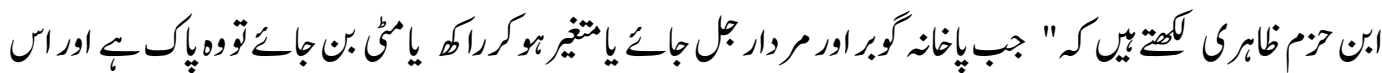

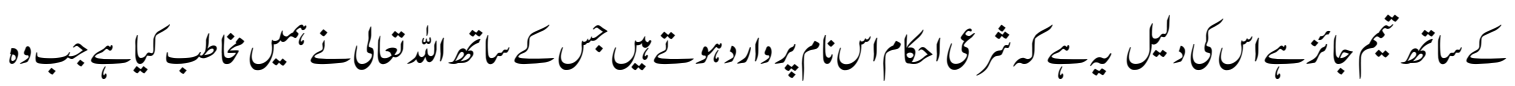

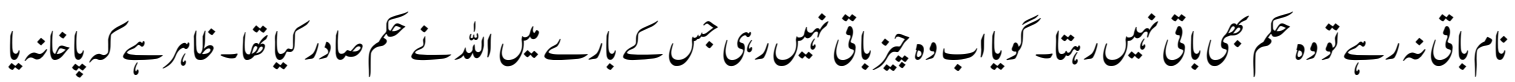

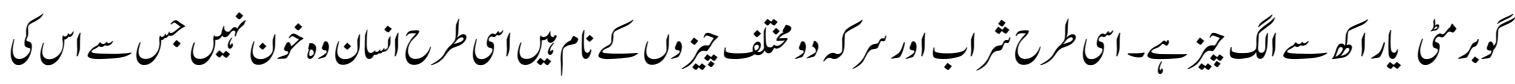

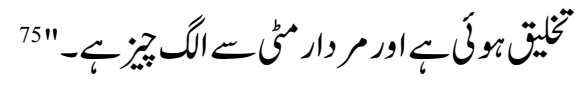

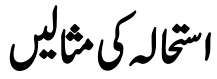

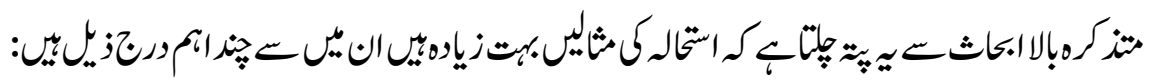

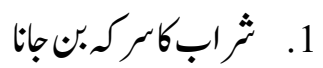

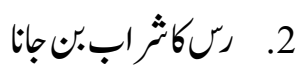
3.

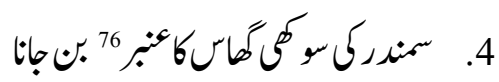

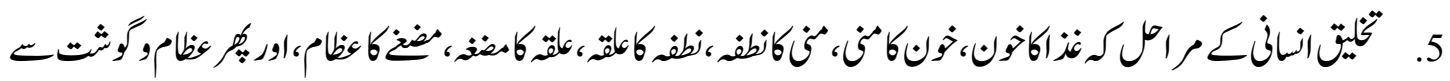

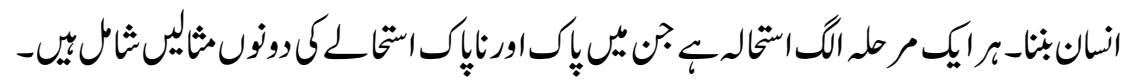

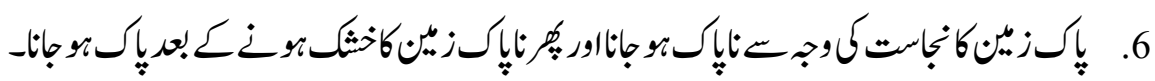

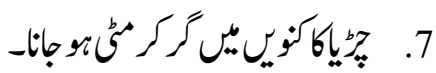

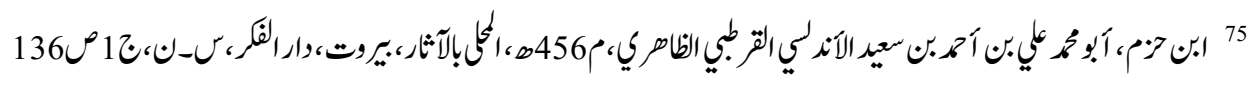

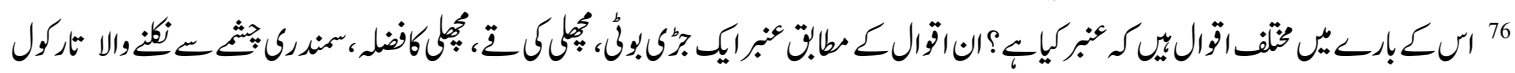

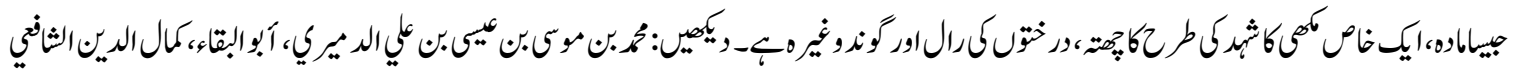

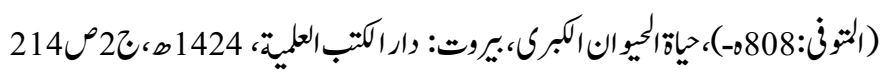




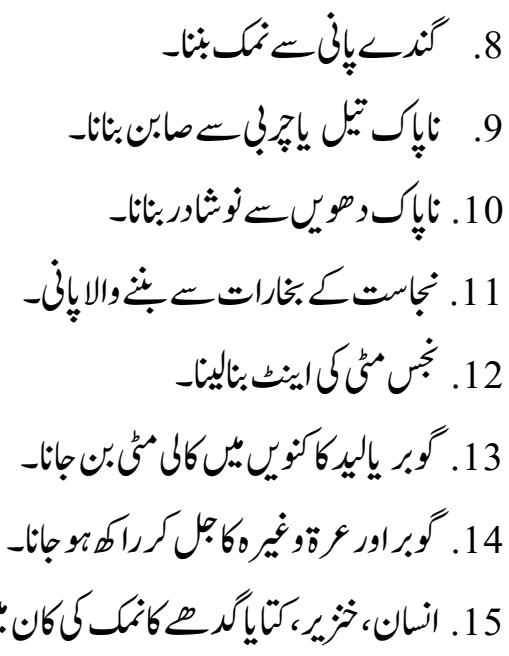

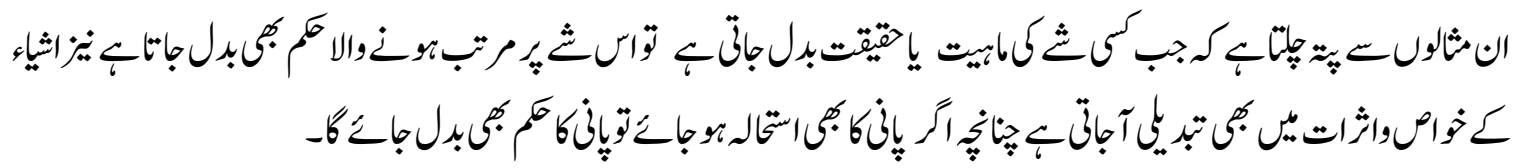

استخاله مريق

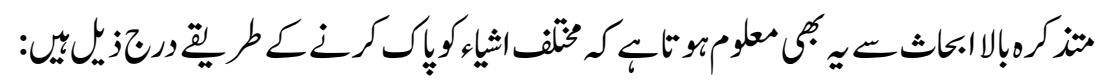

$$
\begin{aligned}
& 1 \\
& \text { 2. } \\
& \text { 3. }
\end{aligned}
$$

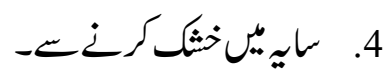

$$
\begin{aligned}
& \text { 5. تُنير آجإنـ }
\end{aligned}
$$

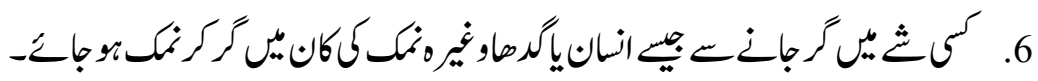

$$
\begin{aligned}
& \text { 7. } \\
& \text { 8. }
\end{aligned}
$$

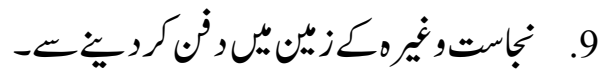

$$
\begin{aligned}
& \text { 10. كيمياوك كمل } \\
& \text { 11. قرنقطوريك- } \\
& \text { 12. طول كمثيامر ورزانهـــ } \\
& \text { 13. }
\end{aligned}
$$




$$
\begin{aligned}
& \text { 14. بهيم ليخ 1. } \\
& \text { 15. زُك } \\
& \text { 16. لنا اوررك كُناـ } \\
& -17 \\
& -\leftarrow^{79} \text { 乙 } \dot{18} \\
& \text { 19. كورونــ } \\
& \text { 20. } \\
& \text { 21. تخور }{ }^{80} \\
& \text { 22. تصرف } \\
& \text { 23. تقير } \\
& \text { 24. جوثرينا_ } 83
\end{aligned}
$$

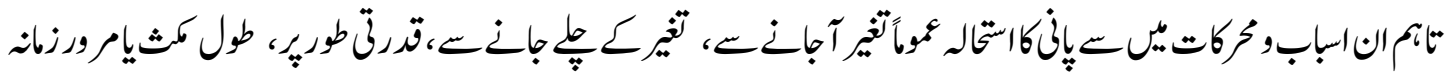

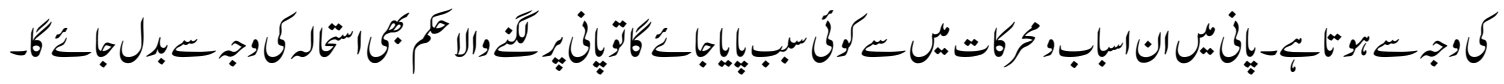

\section{ملاص .كثث}

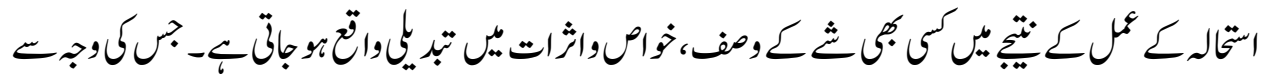

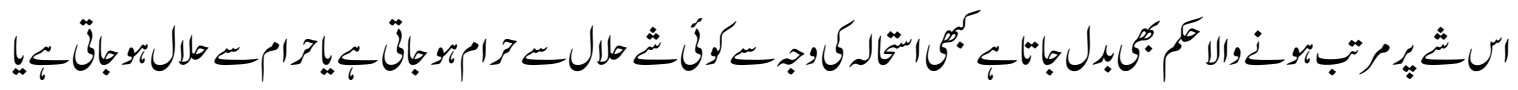

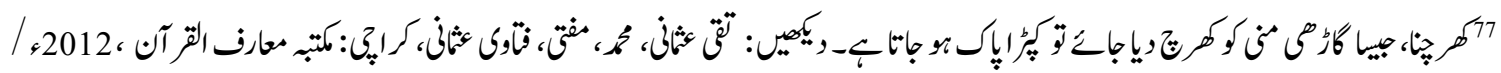

31801433 181818

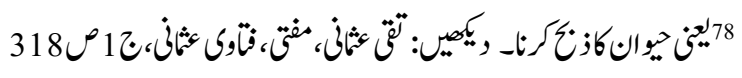

79 189

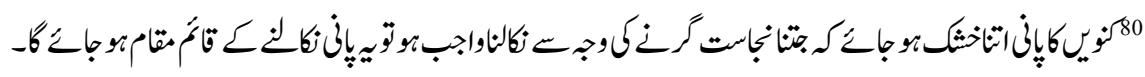

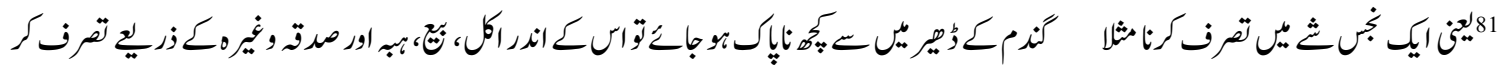

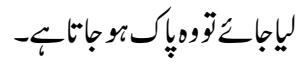

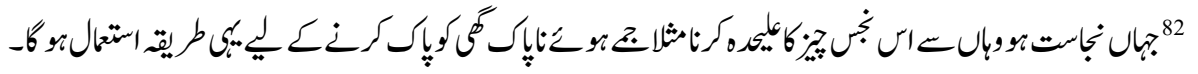

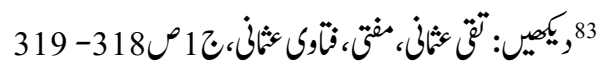




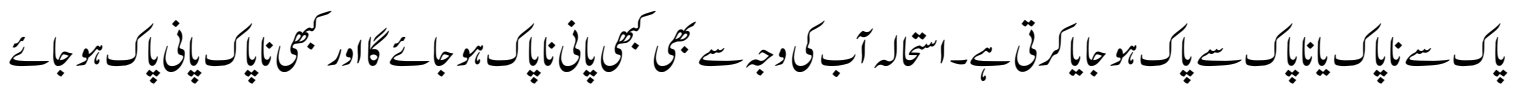

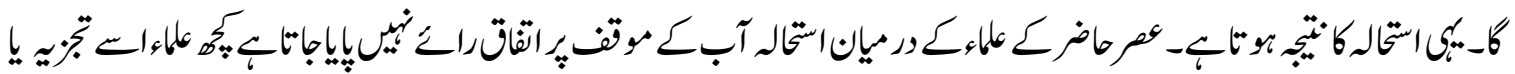

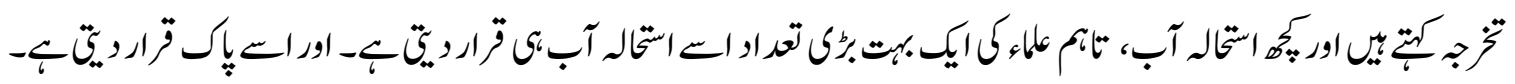

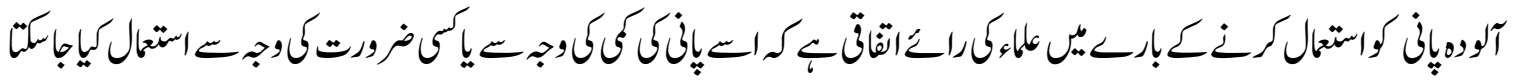

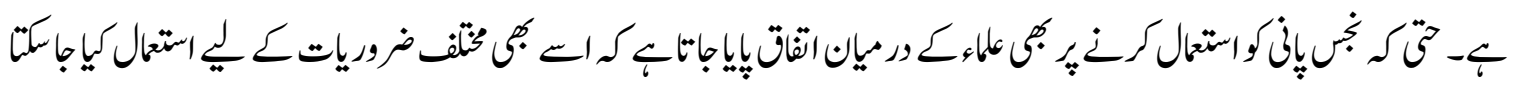

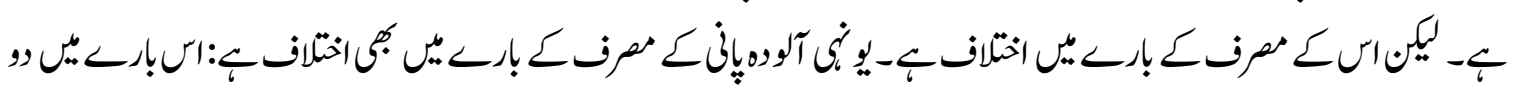

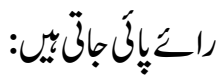

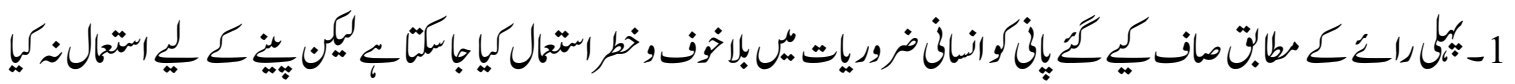

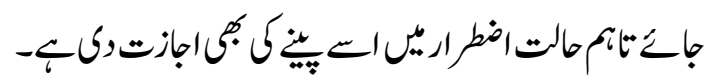

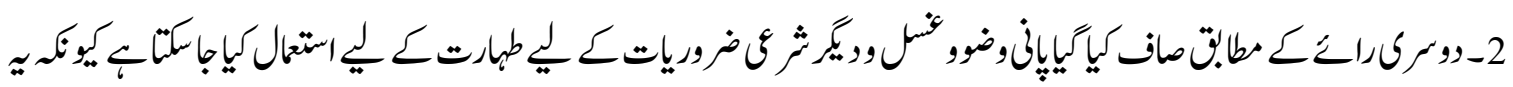

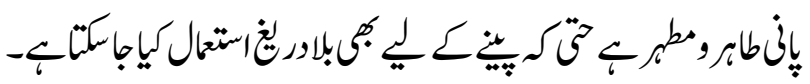

